\title{
Motivation and Volition in the Course of Action
}

\author{
A. Achtziger and P. M. Gollwitzer
}
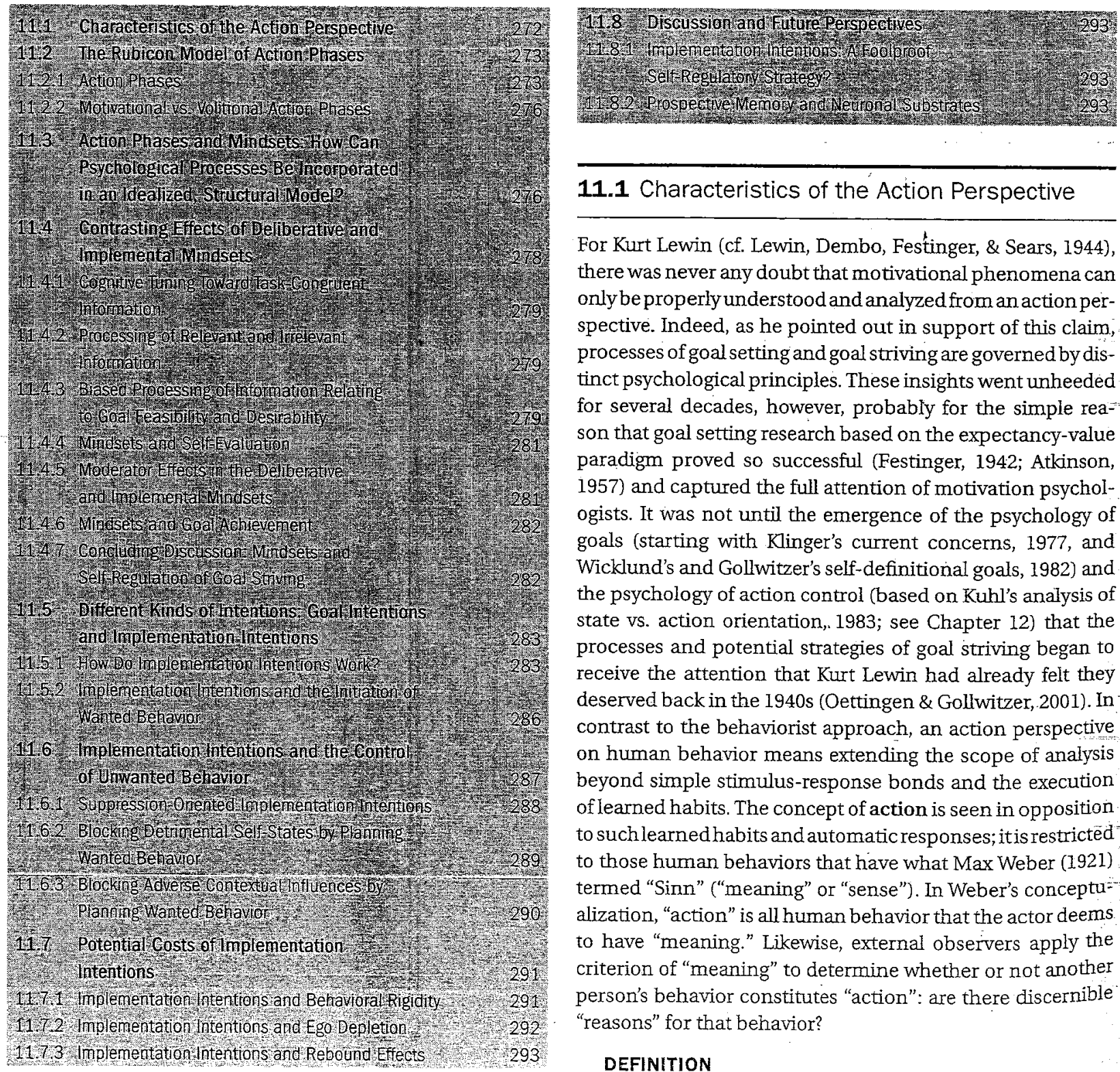

11.1 Characteristics of the Action Perspective

For Kurt Lewin (cf. Lewin, Dembo, Festinger, \& Sears, 1944), there was never any doubt that motivational phenomena can only be properly understood and analyzed from an action perspective. Indeed, as he pointed out in support of this claim; processes of goal setting and goal striving are governed by distinct psychological principles. These insights went unheeded for several decades, however, probably for the simple reason that goal setting research based on the expectancy-value paradigm proved so successful (Festinger, 1942; Atkinson, 1957) and captured the full attention of motivation psychologists. It was not until the emergence of the psychology of goals (starting with Klinger's current concerns, 1977, and Wicklund's and Gollwitzer's self-definitional goals, 1982) and the psychology of action control (based on Kuhl's analysis of state vs. action orientation,. 1983; see Chapter 12) that the processes and potential strategies of goal striving began to receive the attention that Kurt Lewin had already felt they deserved back in the 1940s (Oettingen \& Gollwitzer, 2001). In contrast to the behaviorist approach, an action perspective on human behavior means extending the scope of analysis beyond simple stimulus-response bonds and the execution of learned habits. The concept of action is seen in opposition to such learned habits and automatic responses; it is restricted to those human behaviors that have what Max Weber (1921) termed "Sinn" ("meaning" or "sense"). In Weber's conceptu" alization, "action" is all human behavior that the actor deems. to have "meaning." Likewise, external observers apply the criterion of "meaning" to determine whether or not another person's behavior constitutes "action": are there discernible "reasons" for that behavior?

\section{DEFINITION}

From this perspective, actions can be defined as all activities directed toward an "intended goal." 
The motivation psychology of action focuses on questions of action control. These issues are important because as action psychology research has shown repeatedly-a strong motivation to achieve a certain outcome or engage in a certain behavior does not normally suffice for that behavior to be implemented and the goal to be realized (Gollwitzer \& Bargh, 1996; Heckhausen, 1989; Kuhl, 1983). In fact, successful goal attainment often requires the skilled deployment of various action control strategies (e.g., formulating "if-then" plans, resuming interrupted actions, stepping up efforts in the face of difficulties; cf. Gollwitzer \& Moskowitz, 1996; Sections 11.5-11.7).

\subsection{The Rubicon Model of Action Phases}

The focus of this section is on the course of action, which the Rubicon model of action phases understands to be a temporal, horizontal path starting with a person's desires and ending with the evaluation of the action outcomes achieved (Gollwitzer, 1990; Heckhausen, 1987a; 1989; Heckhausen \& Gollwitzer, 1987). The Rubicon model seeks to provide answers to the following questions:

How do people select their goals?

How do they plan the execution of those goals?

How do they enact these plans?

How do they evaluate their efforts to accomplish a specific goal?

The major innovation of the Rubicon model was to define clear boundaries between motivational and volitional action phases. These boundaries mark functional shifts between mindsets conducive to goal deliberation and mindsets conducive to goal achievement. The three most important boundaries are at the transition from the motivational phase before a decision is made to the subsequent volitional phase, at the transition from this planning phase to the initiation of action, and finally at the transition from the action phase back to the motivational (postactional) evaluation phase.

\subsubsection{Action Phases}

Heckhausen's Rubicon model of action phases was inspired by the necessity to distinguish two major issues in motivation psychology - the selection of a stion goals and the realization of those goals (Lewin, 1926b) - and, at the same time, to incorporate both within a single, unifying framework(Heckhausen, 1987a, 1989; Heckhausen \& Gollwitzer, 1987). In a manner of speaking, the model examines the transition from wishing to weighing in goal selection and from weighing to willing in actual goal pursuit (Heckhausen, 1987b). Importantly, it highlights the distinctions between goal setting and goal striving, and is careful not to confuse or confound the two. It was precisely that kind of indiscriminate approach that generated confusion in the history of motivation psychology, and resulted in volitional phenomena being neglected for decades (Heckhausen, 1987c, 1989; Kuhl, 1983, Gollwitzer, $1990,1991)$. Given that the processes of goal setting and goal striving serve a common function, however, it was important that they should not be seen as isolated, independent phenomena either. The Rubicon model gets around this difficulty by tracking the emergence of a motivational tendency over time - from the awakening of wishes to goal selection and commitment, and finally goal deactivation. It seeks to describe the emergence, maturation, and fading of motivation, dividing a course of action into four natural, consecutive phases separated by clear boundaries or transition points. These four action phases differ in terms of the tasks that have to be addressed before the individual can move on to the next phase. The distinctions the model draws between consecutive action phases are thus both structural and functional in nature.

According to the Rubicon model, a course of action involves a phase of deliberating the positive and negative potential consequences of various nonbinding wishes and action alternatives (predecisional phase), a phase of planning concrete strategies for achieving the goal selected at the end of the predecisional phase (preactional/postdecisional phase), a phase of enacting these strategies (actional phase), and finally a phase of evaluating the action outcome (postactional phase; Fig. 11.1; see also Fig. 1.3 in Chapter 1).

- The four phases of the Rubicon model differ in terms of the tasks that have to be addressed before the individual can move on to the next phase. Motivational episodes are thus broken down into "natural" and seemingly independent phases. Critically, the Rubicon model seeks to explain both goal setting and goal striving.
Figure 11.1 The Rubicon model of action phases. (Heckhausen \& Gollwitzer, 1987)
Intention Intention Intention Intention

Formation Initiation Realization Deactivation

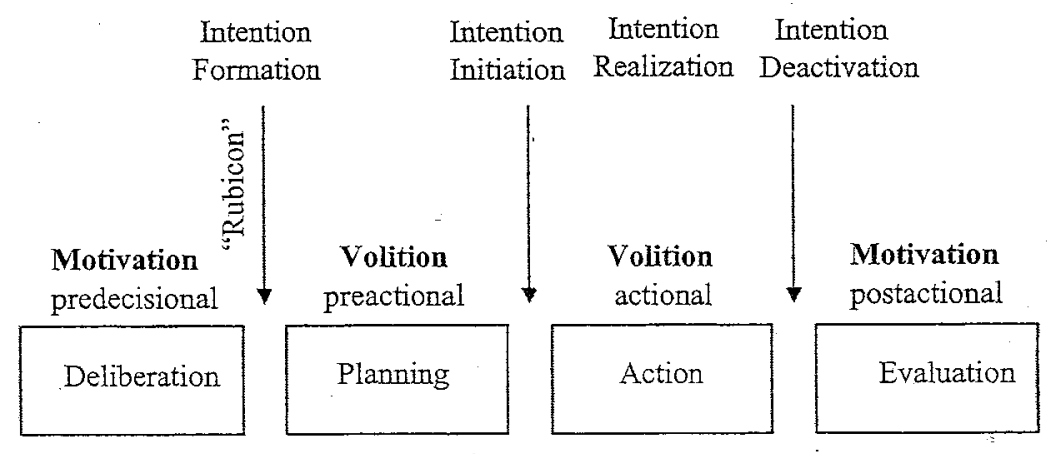


The Predecisional Phase

The first phase (predecisional phase) is characterized by deliberation. An individual first has to decide which of his or her many wishes to pursue. A person's motives are assumed to produce certain wishes. For example, a person with a strong achievement motive (Chapter 6) and a weak affiliation motive (Chapter 7) is expected to experience more wishes related to achievement than to affiliation. Yet because people's needs and motives produce more wishes than can possibly be enacted, they are forced to choose among them, committing themselves to certain selected goals. To this end, they weigh the desirability and feasibility of their many wishes. The objective of the predecisional phase is thus to decide based on the criteria of feasibility (i.e., the expectancy that the action will succeed) and desirability (i.e., the value of the expected action outcome) - which of their wishes they really want to pursue. Individuals contemplating the feasibility of a potential goal will ask themselves questions such as the following:

I Can I obtain the desired outcomes by my own activity (action-outcome, expectancy)?

Is the situational context facilitating or inhibiting (action-by-situation expectancy)?

The following questions are also crucial:

Do I have the necessary time and resources to pursue the desired outcome?

Might favorable opportunities to pursue it arise? The desirability of a potential goal or desired outcome is determined by reflecting on questions such as the following:

What are the short-and long-term consequences of pursuing this goal?

How positive or negative might these consequences be for me?

How probable is it that these consequences will occur? In addressing these questions, the individual weighs the expected value of a wish or potential goal; reflects on its positive and negative, short- and long-term consequences; and assesses the probability that achieving the desired outcome or potential goal will bring about these consequences. It is assumed that people do not contemplate their wishes and potential goals in isolation, but see them in relation to other wishes and potential goals. A wish associated with a number of attractive consequences may thus suddenly appear less desirable in the light of a superordinate wish. Conversely, a wish may appear more feasible when contemplated in the contextof other wishes thar when seenin isolation- The dura= tion of the deliberation process varies from case to case. It is rare for answers to be found to all questions. In fact, many of the questions have no hard and fast answers (e.g., it is difficult to gauge outcome-consequence expectancies when the consequences in question involve external evaluation or progress toward a superordinate goal), and in most cases, there is not even enough time to address all of the questions that might be answered.
The Rubicon model thus postulates the facit (i.e., concluding) tendency to facilitate predictions of when the motivational task of deliberation will be completed. The more thoroughly an individual has weighed the positive and negative short-and long-term consequences of engaging or not engaging in a particular behavior, the closer he or she comes to the belief of having exhausted all possible routes of action. The chances of gaining new insights into potential consequences decrease, and the facit tendency, i.e., the tendency to decide on a certain wish or potential goal, increases apace. However, a decision is only made when a previously stipulated level of clarification has been attained. This level of clarification is positively correlated with the personal importance of the decision and negatively correlated with the costs incurred in acquiring information on potential consequences and thinking that information through. As shown by Gollwitzer, Heckhausen, and Ratajczak (1990), however, the process of deliberation can be shortened by thinking in depth and detail abouthow one of the alternatives under consideration might be translated into action. In an experimental design, these authors found that participants who anticipated a decision and planned their subsequent actions were quicker to make a decision.

However, even a wish with a high resultant motivational tendency (i.e., high expected value and hence high desirability) does not necessarily gain access to the executive. Rather, it first has to be transformed into a concrete goal. This transformation is often described as crossing the Rubicon in allusion to Julius Caesar's crossing of the stream that once marked the boundary between Italy and Cisalpine Gaul. By leading his army across the Rubicon and marching on Rome, Caesar committed himself irrevocably to civil war. The transformation of a wish into a goal involves a shift from a fluid state of deliberating the value of a potential goal to a firm sense of commitment to its enactment, i.e., to the formation of a "goal intention" (see Section 11.5 for a definition of "goal intention"). Phenomenologically, it results in a feeling of determination and certainty of taking the necessary action (Michotte \& Prüm, 1910). The goal specified in the wish thus becomes an end state to which the individual feels committed.

(4) In the predecisional phase, individuals contemplate the feasibility of certain wishes as well as the desirability of potential action outcomes. This process of deliberation culminates in commitment to a specific goal (goal intention) - in crossing the "Rubicon" between wishes and goals. The transformation of a wish into a binding goal or goal intention results in a firm sense of commitment to translate that goal into action.

\section{Preactional Phase}

It may not be possible for newly formed goal intentions to be implemented immediately. The individual may first have to complete other activities, or wait for suitable opportunities to arise. Moreover, many goal intentions specify goal states (e.g., spending more time with one's family, graduating 
from college, etc.) that cannot be achieved instantly. Consequently, people may be forced to wait for favorable opportunities to arise before progressing toward the intended goal state. According to the Rubicon model, individuals in this waiting stage are in the second phase of a course of action the volitional preactional (or postdecisional) phase. The term "volition" indicates that the motivational deliberation of potential action goals has been terminated by crossing the Rubicon, and that the individual is now committed to achieving a specific goal state. The task facing individuals in this postdecisionai (but preactional) phase is to determine how best to go about attaining the chosen goal. Thus, it is no longer a question of selecting desirable and feasible goals, but of determining how to facilitate the achievement of the goals chosen; e.g., by means of routine behaviors that are more or less automatic or newly acquired behaviors that require conscious thought. Ideally, people in the preactional phase should also develop plans specifying when, where, and how goal-directed behavior is to be performed (Gollwitzer, 1999). These plans are called implementation intentions (Section 11.5).According to the Rubicon model and the theory of intentional action control (Gollwitzer, 1993, 1999), implementation intentions concerning the initiation, execution, and termination of actions help people to overcome the difficulties that can be anticipated as they progress toward their goals. People often find it particularly difficult to get started, instead engaging in extended procrastination and overlooking viable opportunities to initiate goal-facilitating behavior. These are the problems to be overcome in the second phase of action.

How, then, is action initiated when a more or less favorable opportunity arises? The concept of the fiat tendency was introduced to answer this question. By crossing the Rubicon, people commit themselves to enacting their chosen goals. The strength of this commitment, which the Rubicon model labels volitional strength, is a positive linear function of the strength of the corresponding motivational tendency (i.e., the desirability and feasibility of the intended goal). The strength of a goal intention's fiat tendency is the product of its volitional strength (i.e., the commitment to pursuing the goal state) and of the suitability of the situation for its initiation. The suitability of a situation is not determined in isolation, but relative to other opportunities that might occur in the future (longitudinal competition). The fiat tendencies of an individual's other goal intentions also have to be considered. It would be wrong to assume that people always take action to promote a goal with a high fiat tendency. Many situations are conducive to a whole range of intentions, not all of which can be implemented at once (cross-sectional competition). In this case, the goal intention with the highest fiat tendency gains access to the executive, and actions seeking to accomplish it are initiated.

In the preactional phase, individuals contemplate how best to pursue the goal to which they committed at the end of the predecisional phase. They choose strategies and formulate plans (e.g., implementation intentions; see also Section 11.5) that seem conducive to attaining the aspired goal state.

\section{Actional Phase}

The initiation of action designed to further the plans formulated in the preactional phase signals the transition to the actional phase. In this phase, the individual's efforts are focused on pursuing goal-directed actions and bringing them to a successful conclusion. These efforts are best facilitated by steadfast pursuit of goals, which implies stepping up effort in the face of difficulties, and resuming goal-directed actions after every interruption. Whether or not an action is executed is determined by the volitional strength of the goal intention. The level of volitional strength acts as a kind of threshold value for effort exertion. Although this threshold is primarily determined by the strength of the motivational tendency, it may be spontaneously shifted upward when situational difficulties are encountered. The primary source of increased volition is the extra effort mobilized in response to situational difficulties. In this phase, action implementation is guided by the mental representation of the goal to which the individual has committed, which may well be outside his or her conscious awareness.

(1) In the actional phase, individuals seek to enact the plans made in the preactional phase with the aim of enacting the goal formulated at the end of the predecisional phase. These efforts are best facilitated by steadfast pursuit of the goal and by stepping up the effort exerted in the face of difficulties.

\section{Postactional Phase}

The transition to the fourth and final action phase, the postactional phase occurs once the goal-oriented actions have been completed. The task to be addressed at this stage is again a motivational one. Specifically, individuals measure the results of their actions against the goal set at the end of the predecisional phase, asking questions such as the following:

How well have I succeeded in achieving my goal?

Did the action result in the positive consequences anticipated?

Can I now consider my action intention completed?

If the goal was not attained, do I need to keep working toward it, perhaps by other means?

Individuals in the postactional phase thus look back at the action outcome attained and, at the same time, cast their thoughts forward to future action. If the action outcome corresponds with the aspired goal state, the underlying goal is deactivated. In many cases, shortcomings in the predecisional deliberation of an action's positive and negative, shortand long-term consequences may become apparent at this point. It may, for example, emerge that the desirability of the goal was overrated because certain outcome expectancies: 
were overestimated or overlooked. Of course,..not all comparisons between intended and achieved outcomes result in the deactivation of the goal: the action outcome may deviate from the intention in qualitative or quantitative terms. The goal may then be adjusted to the outcome by lowering the level of aspiration. Alternatively, individuals may choose to retain the original goal despite the unsatisfactory outcome, and renew their attempts to achieve it. Deactivation of a goal that has not been achieved seems to be facilitated by the prospect of a new goal taking its place. For example, Beckmann (1994) showed that participants could only detach mentally from a poor score on an intelligence test if they expected a new test to be administered in the next round. Participants who did not have this prospect kept thinking about the poor test result, i.e., engaged in self-evaluative rumination.

(4. In the postactional phase, individuals evaluate the action outcome achieved. If they are satisfied with the outcome, they deactivate the goal set at the end of the predecisional phase. If they are not satisfied with the outcome, they either lower the level of aspiration and deactivate the goal, or retain the original level of aspiration and increase their efforts to achieve the desired goal.

\subsubsection{Motivational vs. Volitional Action Phases}

Kurt Lewin (1926b) and Narziss Ach (1935) understood volition to be the form of motivation involved in goal striving, and goal striving to encompass all processes of motivational regulation that serve the pursuit of existing goals. Thus, volition concerns the translation of existing goals into action and, specifically, the regulation of these processes. Motivation, in contrast, concerns the motivational processes involved in goal setting. The focus here is on which goals a person wishes to pursue. People who have to decide between different goals are assumed to weigh the expected value and attainability of the available options very carefully (Gollwitzer, 1990). Classic motivation theories rely on this narrow definition of motivation, assuming the motivation to act to be determined by both the desirability and perceived feasibility of the aspired goal. If someone does not believe him- or herself capable of doing what is needed to attain a goal, or does not consider a goal particularly desirable, he or she will not be motivated to do all she can to pursue it.

In the early 1980s, Kuhl reestablished the distinction between motivation and volition, and drew a clear line between modern volition research and the more philosophical debate on "free will" (Kuhl, 1983; see also Chapter 12). Kuhl was the first modem motivation researcher to draw attention to the contrasting functions and characteristics of "choice motivation" and "control motivation," and strongly advocated that a distinction be made between motivational and volitional issues in research (Kuhl, 1983, 1984, 1987).

\section{SUMMARY}

Motivation concerns the processes and phenomena involved in goal setting, i.e., the selection of goals on the basis of their desirability and feasibility. Motivational processes dominate in the predecisional and postactional phases of the Rubicon model. Volitional processes and phenomena, on the other hand, concern the translation of these goals into action. Volitional processes dominate in the preactional and actional phase.

11.3 Action Phases and Mindsets: How Can Psychological Processes Be Incorporated in an Idealized, Structural Model?

The Rubicon model of action phases implies that goaldirected behavior can be broken down into a series of consecutive phases. The premise for this kind of research approach is that the phases identified describe qualitatively different psychological phenomena that correspond to the different functions of each action phase. The Rubicon model is thus both structural and functional in nature (Heckhausen, 1987a). The main functions of the four action phases identified are listed in the following overview.

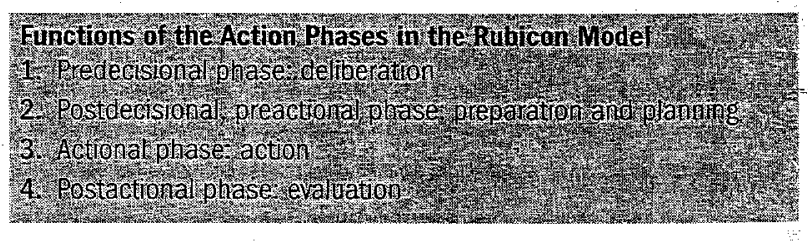

Each of these functions is assumed to be associated with a different mindset; i.e., a form of information processing that is appropriate to the action phase at hand. Based on the terminology of the Würzburg school (Chapter 2), the concept of mindset refers to the states of mind that are associated with the assumption and execution of specific tasks (Marbe, 1915; Heckhausen, 1989).

\section{DEFINITION}

The term "mindset" describes a certain kind of cognitive orientation that facilitates performance of the task to be addressed in each action phase.

Mindset research is based on the idea that distinct tasks have to be solved in each phase of the Rubicon model (Gollwitzer, 1990).

In their comprehensive research program, Gollwitzer and colleagues (see the overview in Gollwitzer, 1991) have found evidence for qualitative differences between action phases, and they have shown that task-congruent mindsets determine the content and form of information processing in each action phase. Within the research paradigm founded by Gollwitzer, the characteristic task demands of the deliberation, implementation, action, and evaluation phases are first 
analyzed, allowing hypotheses about phase-specific differences in information processing to then be derived and systematically tested (Gollwitzer, 1990; Gollwitzer \& Bayer, 1999). These hypotheses, which are outlined below, concern the cognitive orientations that are functional for addressing phasespecific tasks. It is assumed that each phase is associated with a certain mindset (i.e., with the activation of specific cognitive procedures) that facilitates performance of the task at hand.

\section{Deliberative Mindset}

The deliberative mindset is associated with the predecisional phase and thus with the task of goal setting. What kind of cognitive orientation characterizes this mindset? How do people in this mindset attend to and process information? Individuals in the predecisional phase are faced with the task of deciding which of their wishes to translate into action; they have to weigh the relative desirability and feasibility of their wishes in order to select comparatively attractive and attainable action goals. Solving this task requires individuals in the deliberative mindset to be primarily concerned with information about the incentives (desirability) of different goals and expectancies (feasibility) of attaining them. The positive and negative incentives and/or potential consequences of specific action outcomes also have to be considered as impartially as possible; it is important that negative consequences should not be overlooked. Likewise, feasibility assessments should be as accurate as possible, i.e., neither overly optimistic nor unnecessarily pessimistic. Only if expectancies and incentives are assessed in an objective and impartial manner can the predecisional task of selecting a comparatively desirable and attainable goal be accomplished successfully.

\section{Implemental Mindset}

The implemental mindset is associated with the preactional phase; its task is to prepare for goal strivir ${ }_{6}^{\prime}$; e.g., by undertaking efforts to initiate appropriate actions. The concrete approach taken depends on the type of goal set. If, upon crossing the Rubicon, the goal was furnished with implementation intentions (Sections 11.5-11.7) specifying when, where, and how actions are to be initiated, all that remains to be done is to wait for an appropriate opportunity to arise (i.e., the "when" and "where" specified in the implementation intention). As soon as a potentially viable opportunity arises, the individual compares it with the opportunity defined as favorable in the implementation intention. If a match is ascertained, goal-directed behavior is initiated immediately. The same holds for goals that do not require implementation intentions because they are habitually initiated in a specific way. Here, too, the individual simply has to wait for a suitable opportunity to arise, and then initiate goal-directed behavior. If neither implementation intentions nor habits that might facilitate goal achievement are in place, corresponding action plans first have to be formulated. Solving these tasks requires individuals to, be receptive to and process information that facilitates the initiation of goal-oriented behavior, and that prevents its postponement. To this end, there is cognitive tuning toward information relevant to where, when, and how to act. At the same time, there should be closed-mindedness in the sense that people should concentrate on information relevant to task performance, and ignore incidental, less relevant information. Thus, attention is focused on a specified opportunity to act, and the individual is shielded from the distractions of competing goals, etc. This shielding function also applies to information about the desirability and feasibility of the-goal selected at the end of the predecisional phase, which is irrelevant to the initiation of goal-directed behavior and is, in fact, distracting.

8 Individuals in the implemental mindset are particularly receptive to information relating to the initiation of goal-directed behavior. At the same time, there is closed-mindedness in the sense that only information that will help to promote the chosen goal is processed.

\section{Actional Mindset}

The actional mindset is associated with the actional phase, the task of which can be described as acting toward the goal such that goal achievement is promoted. Solving this task requires individuals to avoid disruptions in goal-facilitating behavior, because any halting of the flow of action postpones goal achievement. The actional mindset should therefore evidence characteristics of what Csikszentmihalyi (1975) called "flow experience" and Wicklund (1986) labeled "dynamic orientation." Specifically, individuals in this mindset no longer reflect on the qualities of the goal to be achieved, or on their abilities and skills to achieve that goal. They do not consider alternative strategies, neither do they form implementation intentions or action plans specifying when, where, and how to act. Rather, they are totally absorbed in the actions being executed. Accordingly, they only attend to those aspects of the self and the environment that sustain the course of action, and ignore any potentially disruptive aspects (e.g., self-reflective thoughts, competing goals, or distracting environmental stimuli). The actional mindset is therefore hypothesized to be one of closed-mindedness to any information that might trigger reevaluation of the goal selected at the end of the predecisional phase, reevaluation of the implementation strategy chosen, or any form of self-evaluation (e.g., "Can Ibe proud of my performance thus far?", "Do Ihave the necessary skills to achieve the goal?"). Rather, the actional mindset should evidence cognitive tuning toward internal and external cues that guide the course of action toward goal attainment. This information should be as accurate as possible; its evaluation should not be positively biased. The actional mindset should emerge whenever people move effectively toward goal attainment.

\section{Evaluative Mindset}

The evaluative mindset is associated with the postactional phase, when the task is to evaluate the action outcome and its consequences in order to establish whether goal pursuit 
has led to the intended outcome and desired consequences. Solving this task requires individuals to be primarily concerned with the quality of the action outcome and the actual desirability of its consequences. In other words, individuals in the evaluative action phase compare what has been achieved (outcomes) and obtained (consequences) with what was originally expected or intended. Accurate assessments of the quality of the outcome and objective, impartial views of the desirability of its consequences are thus required. Accordingly, the evaluative mindset should evidence the following characteristics:

- cognitive tuning toward information relevant to assessing the quality of the achieved outcome and the desirability of its consequences,

accurate and impartial processing of that information, and

- a comparative orientation: the intended outcome and its expected consequences are compared with the actual outcome and its consequences.

\section{SUMMARY}

The action phases of the Rubicon model are characterized by four distinct goal-oriented behaviors: deliberating, planning, acting, and evaluating. Because each phase involves a distinct task, each is associated with a mindset conducive to performing that task. The cognitive characteristics of each mindset can be specified by critically analyzing the demands of the tasks addressed in each action phase. For example, the deliberative mindset is characterized by open-mindedness, and by the objective processing of all available information on the potential consequences of an action outcome (desirability) and the viability of the individual's wishes (feasibility). The implemental mindset is characterized by cognitive tuning toward information that facilitates the initiation of goaloriented behavior, and that prevents its postponement. The actional mindsetfocuses attention on those aspects of the self and the environment that sustain the course of action; any potentially disruptive aspects (e.g., self-reflective thoughts, competing goals, or distracting environmental stimuli) are ignored. Finally, in the evaluative mindset, there is cognitive tuning toward information that helps to assess the quality of the achieved outcome as objectively and accurately as possible. To this end, the individual compares what has actually been achieved (action outcome) and obtained (consequences of that outcome) with the intended or expected outcomes and consequences.

11.4 Contrasting Effects of the Deliberative and Implemental Mindsets

Having discussed the theoretical background to the four mindsets in Section 11.3, we now present empirical findings in support of the hypotheses formulated about the deliberative and implemental mindsets. We focus on these two mindsets simply because research has yet to examine the actional and evaluative mindsets, or to test the hypotheses derived about information processing and cognitive orientations in these last two phases of the Rubicon model. We begin by describing how the deliberative and implemental mindsets can be induced experimentally.

\section{STUDY}

\section{Experimental Design Comparing Deliberative} and Implemental Mindsets

Induction of the Deliberative Mindset:

Participants are asked to identify a personal concern (problem) that they are currently deliberating, without yet having decided whether to make a change (i.e., to act) or to let things take their course (i.e., to remain passive). For example, they may be contemplating whether it makes more sense to switch majors or to stick with their current one. Participants are then asked to list the potential short-term and long-term, pdsitive and negative consequences of making or failing to make a change decision, and to estimate the probability of those consequences actually occurring (cf. Gollwiter \& K.nney, 1989, Study 2; Gollwitzer \& Bayen 1999).

Induction of the Implemental Mindset:

Participants are asked to identify a goal (project) that they intend to accomplish within the next three months; e.g., applying for a grant to study abroad. They then list five steps that have to be taken to accomplish that goal, and finally write down concrete plans on when, where, and how to take each step. They thus specify the exact time, place, and manner in which each step toward realizing the goal is to be taken (cf. Gollwitzer \& Kinney, 1989, Study 2; Gollwitzer \& Bayer, 1999).

alternative Means of Induction:

Puca (2001) and Puca and Schmalt (2001) induced the deliberative mindset by interrupting the decision-making processes of participants who were poised to make a decision, such that they continued to deiberate on the alternatives available. They induced the implemental mindset by allowing participants to make a decision (between alternatives). Participants were then administered tasks that had nothing to do with the decision task, but served to investigate the effects of the respective mindset on different cognitive processes. Gollwitzer and Kinney (1980,-Study 1)-had-already taken a similar approach, inducing an implemental or a deliberative mindset by presenting participants with a decision task. Specifically, the implemental mindset was induced by asking participants to decide on a certain sequence of trials before the dependent variables were assessed. The deliberative mindset was induced by interrupting participants shortly before they made a final decision on a sequence of trials. 


\subsubsection{Cognitive Tuning Toward Task-Congruent Information}

The implemental mindset is assumed to promote goal attainment by helping people to overcome the classic problems of goal striving; e.g., doubting the attractiveness and hence the desirability of the goal being pursued, the practicability of goal-directed strategies, or the feasibility of the aspired project. Empirical data support these assumptions, showing that the implemental mindset evckes cognitive tuning toward information related to goal attainment. Participants in an implemental mindset report more thoughts relating to the execution of an aspired project (i.e., "implemental" thoughts of the type "I'II start with $X$ and then move on to $\left.Y^{\prime \prime}\right)$ than participants in a deliberative mindset (who tend to report "deliberative" thoughts of the type "If I do this, it will have positive/negative consequences, if I don't, then $\mathrm{X}, \mathrm{Y}$, or Z is likely to happen"; cf. Heckhausen \& Gollwitzer, 1987; Taylor \& Gollwitzer, 1995, Study 3; Puca \& Schmalt, 2001).

In a series of studies, Gollwitzer, Heckhausen, and Steller (1990) induced either an implemental or a deliberative mindsetusing the procedure described in Section 11.4. Participants were then presented with three fairy tales that were cut short at a certain point in the plot. In what was ostensibly a creativity test, they were asked to continue the story. Participants in the implemental mindset were more likely to have the protago-nists of their stories plan how to carry out a chosen goal than were participants in the deliberative mindset. In a second study, participants in an implemental or a deliberative mindsetwere shown a series of slides, each presenting an image of a person along with sentences reporting that person's thoughts on the pros and cons of a specific course of action and plans to put it into practice. After viewing the slides and working on a short distracter task, participants were administered a cued-recall test of the information presented. Implemental participants were better able to recall information relating to the when, where, and how of goal achievement than information relating to the pros and cons of a change decision. The recall performance of deliberative participants showed the reverse pattern.

\section{SUMMARY}

The thoughts of individuals in the deliberative mindset are more attuned to action alternatives than to strategies of goal achievement; likewise, individuals in the deliberative mindset recall information associated with the deliberation of alternatives better than information pertaining to the accomplishment of goal-directed actions. Individuals in the implemental mindset devote more thought to planning goal-directed behavior than to contemplating action alternatives, and find it easier to recall information relating to the planning of actions than to the contemplation of action alternatives.

\subsubsection{Processing of Relevant and Irrelevant Information}

Gollwitzer and Bayer (1999) report that the implemental mindset leads to "closed-mindedness," to the extent that individuals in this mindset do not allow themselves to be distracted by irrelevant information, but focus exclusively on information relevant to the accomplishment of their goal. This finding is substantiated by the empirical data of Heckhausen and Gollwitzer (1987, Study 2), who found that implemental participants have shorter noun spans (a good indicator of reduced cognitive processing speed; Dempster, 1985) than do deliberative participants. A set of studies using a modified Müller-Lyer task confirmed that implemental participants' attention is more centrally focused than that of deliberative participants, and that people in a deliberative mindset are more likely to attend to incidental information than people in an implemental mindset (Gollwitzer \& Bayer, 1999). In a decision experiment that required respondents to choose between the Rubicon model and Festinger's dissonance theory, Beckmann and Gollwitzer (1987) showed that information relevant to the ongoing action is processed preferentially in the implemental mindset, even when it is not in line with the decisions that have been made.

\section{SUMMARY}

Empirical research has shown that people in the deliberative mindset are more likely to be distracted by information that is irrelevant to goal attainment. This finding is in line with the observation that individuals in the deliberative mindset attend to incidental information. The reverse holds for the implemental mindset. Here, processing is attuned to information of direct relevance to goal attainment, and attention is centrally focused.

\subsubsection{Biased Processing of Information Relating to Goal Feasibility and Desirability}

Mindset research assumes that the implemental mindset fosters a positive evaluation of the chosen goal (i.e., its high desirability) and, at the same time, promotes a highly optimistic assessment of its practicability and attainability. The deliberative mindset, by contrast, is assumed to generate objective assessments of the positive and negative consequences of goal attainment, and a more careful evaluation of the probability of achieving the goal. Various studies (cf. Gollwitzer, 1990) have been conducted to test these hypotheses; one of the classic studies is described on the next page. 


\section{STUDY}

Classic Study on "Illusionary Optimism" in the Implemental Mindset

In what is known as the "contingency learning task" (Alloy \& Abramson, 1979), participants perform a series of triais on a singlestimulus apparatus. Their task is to determine to what degree they can influence the onset of a target light (i.e., the intended outcome) by choosing to press or not press a button. In other words, participants are told that alternative actions (pressing the button/not pressing the button) can lead to the outcome "target light onset." What they do not know is that target light onset is in fact entirely independent of whether or not they press the button; it is determined by a random generator.

The experimenter can vary the apparent degree of control by changing the setting of the random generator, thus manipulating the frequency of target light onset associated with each of the action alternatives (i.e., pressing or not pressing the response button). An extensive body of research using this contingency learning task (cf. Alloy \& Abramson, 1988) has shown that nondepressed particifants believe themselves to have control over target light onset when this desired outcome occurs frequently (e.g., when the target light comes on in $75 \%$ of pressing and $75 \%$ of nonpressing responses) as compared to infrequently (e.g., when the target light comes on in $25 \%$ of pressing and $25 \%$ of nonpressing responses). Given that target light onset is in fact noncontingent to participants' actions, but governed by a random generator, these findings of inaccurrate, optimistic judgments of control are remarkable.

Gollwitzer and Kinney (1989) assumed that this unrealistic illusion of control over target light onset would be less pronounced in deliberative mindset participants than in the implemental mindset participants. The authors assumed that people in the implemental mindset tend to see themselves and their abilities in a much more positive light than do people in the deliberative mindset (Section 11.4). They therefore modified the contingency learning task by adding a second apparatus and asking participants to work on 5 sets of 20 trials. A single trial consisted of the choice to press or not press the response button followed by task light onset or non-onset. A deliberative mindset was induced by telling participants that their objective in the first part of the experiment was to decide which of the two available apparatuses to work on during the second part of the experiment. Deliberative participants were encouraged to try out both apparatuses before the experiment proper began to ensure an informed decision. The implemental mindset was induced by asking participants to specify which apparatus they would use-in-each trial beiore starting the first set. After making this decision, they were instructed to try to produce as many light onsets as possible, whether by pressing or not pressing the response button. The participants were thus instructed to "find out" for themselves whether pressing or not pressing the button gave them more "control" over target light onset. Of course, the experimenter knew that target light onset was in fact governed by a random generator, and entirely independent of participants' actions. Besides the two mindsets, a "target light onset" condition was implemented:

wher the "high frequency of target light onset" condition, in which the target light comes on in $75 \%$ of pressing and $75 \%$ of nonpressing responses

or the "low frequency of target light onset" condition, in which the target light comes on in $25 \%$ of pressing and $25 \%$ of nonpressing responses.

Accordingly, both apparatuses presented either noncontingent frequent or noncontingent infrequent onset of the target light. When target light onset was frequent and thus seemed to be "contingent" on participarits' actions (pressing/not pressing the response button), implemental mindset participants reported inaccurately high judgments of the degree of control they exerted over target light onset (illusionary optimism), whereas deliberative mindset rated their level of control to be much lower. The deliberative mindset participants evidently recognized that high frequency of an event was not necessarily a valid indicator of their own influence over it. The deliberative mindset thus seems to prevent people from adopting unrealistically optimistic beliefs about how much influence they have over uncontrollable events. When, on the other hand, target light onset was infrequent and thus seemingly noncontingent, both mindset groups showed rather modest control judgments. This finding indicates that people in an implemental mindset can adapt to external constraints if necessary. If environmental feedback tells them otherwise (e.g.; a , ilgh rate of "non-hits" in the button-press task), they do not cling blindly to a belief of being in control over target outcomes, but abandon this illusion of control.

On the subject of "illusionary optimism" in the implemental mindset, Gagné and Lydon (2001a) report that individuals in an implemental mindset see the future of their current romantic relationship in a more optimistic light than do individuals in a deliberative mindset. Likewise, Puca (2001, Studies 1 and 2) established that the implemental mindset is associated with an optimistic approach to the choice of test materials of varying difficulty (Study 1) and the prediction of future task performance (Study 2). Relative to deliberative participants, implemental participants opted for more difficult tasks and were more optimistic about their chances of success. Finally, Harmon-Jones and Harmon-Jones (2002, Study 2) discerned differences between the deliberative and implemental mindsets in terms of how information on the desirability of chosen and nonchosen alternatives is processed. Dissonance research discovered that, once a choice has been made, the chosen option is seen in a much more positive light than the nonchosen option. Harmon-Jones and Harmon-Jones observed that induction of an implemental mindset increases this effect, whereas induction of a deliberative mindset reduces it. 


\section{SUMMARY}

Relative to the deliberative mindset, the implemental mindset is associated with increased optimism about the degree of personal control over intended action outcomes and with a preference for difficult tasks. Moreover, the implemental mindset is associated with higher estimations of the probability of success than the deliberative mindset.

\subsubsection{Mindsets and Self-Evaluation}

Deliberative and implemental mindsets have also been shown to affect the way people see themselves. Experimental findings show that people in a deliberative mindset score much lower on the Rosenberg Self-Esteem Scale (Rosenberg, 1965) than do people in an implemental mindset. Likewise, students judge themselves to be more creative, intelligent, popular, etc., when an implemental mindset is induced than when a deliberative mindset is induced (Taylor \& Gollwitzer, 1995). Induction of an implemental mindset evidently boosts people's belief in themseives and their abilities. Where selfratings of susceptibility to various risks are concerned, moreover, findings show that people in an implemental mindset consider themselves less likely to fall victim to various strokes of fate (e.g., being involved in a plane crash or developing diabetes) than do people in a deliberative mindset. Table 11.1 presents the results of this study.

\subsubsection{Moderator Effects in the Deliberative and Implemental Mindsets}

Mindset research has now also established that the effects of deliberative and implemental mindsets are moderated by both individual differences (see the following overview) and context variables (cf. Gollwitzer, 2003).

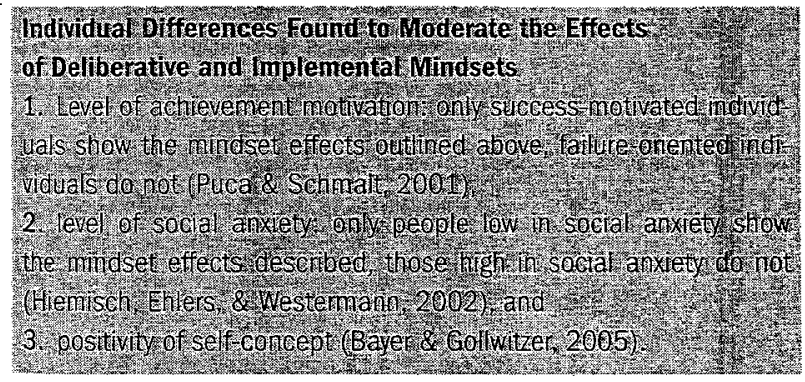

Bayer and Gollwitzer (2005) discovered that students with a high self-view of intellectual capability look for both positive and negative information that is highly diagnostic with respect to their achievement potential when in a deliberative mindset, but focus only on positive information, whether its diagnosticity is high or low, when in an implemental mindset. In contrast, individuals with a negative self-view of intellectual capability focus on positive information (irrespective of its diagnosticity) when in a deliberative mindset and look for highly diagnostic information, whether positive or negative, when in an implemental mindset.

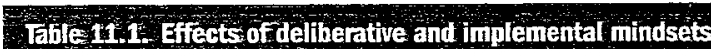
on different vapitiles (Joulor \& Gollinzer 1995 )

\begin{tabular}{lccc} 
& \multicolumn{3}{c}{ Mindsets } \\
\cline { 2 - 4 } $\begin{array}{l}\text { Dependent } \\
\text { variables }\end{array}$ & Control & Deliberative & Implemental \\
\hline Mood & 10.05 & -2.52 & 11.30 \\
Risk & 6.05 & 6.00 & 9.71 \\
Self-esteem & 41.77 & 37.55 & 41.08 \\
Optimism & 30.55 & 27.36 & 29.03 \\
\hline
\end{tabular}

Scores measured on the following scales: mood: Multiple Affect Adjective Checklist (MAACL; Zuckerman \& Lubin, 1965); risk: Measure of Relative Perceived Risk (Perloff \& Fetzer, 1986); self-esteem: Rosenberg Self-Esteem Scale (Rosenberg, 1965); optimism: Life Orientation Test (LOT; Scheier \& Carver, 1985).

The situational context has also been shown to moderate the effects of deliberative and implemental mindsets. To date, research on this aspect has focused on predictions on the stability of participants' romantic relationships (Gagné \& Lydon, 2001a; Gagné, Lydon, \& Bartz, 2003). For example, Gagné and Lydon (2001a) found that deliberating on decisions that have already been made can initiate defensive processing of relationship-related information. Participants who were involved in a romantic relationship were asked to consider the positive and negative consequences of a goal decision that was either associated with the relationship or had nothing to do with relationships in general, and the probability that those consequences would occur (see Section 11.4 for details of mindset induction). Gagné and Lydon found that participants gave their partner much higher ratings if the goal decision they had considered was related to the relationship than if it was not. Interestingly, the partner ratings given by participants in a deliberative mindset were more positive than those given by participants in an implemental mindset. Gagné and Lydon (2001a) concluded that deliberation on one's relationship may be perceived as threatening, and that participants evaluated their partner in more positive terms in order to ward off this threat. In a further study, Gagné \& Lydon (2001b) assessed the commitment participants felt to their relationship using a questionnaire measure. It emerged that only high-commitment participants boosted their ratings of their partner to defend their relationship against the threat posed by deliberating on a relationship problem; lowcommitment participants did not. Thus, commitment to the relationship is another important moderator of the effects of the deliberative and implemental mindset in the context of romantic relationships.

\section{SUMMARY}

Self-concept and the context of romantic relationships have been shown to moderate the effects of deliberative and implemental mindsets. Self-concept moderates mindset effects on the processing of high or low diagnostic information about 


\begin{tabular}{|c|c|c|}
\hline- & Deliberative mindset & implemental mindset \\
\hline \multirow[t]{3}{*}{ Effects on self-concept } & Low assessment of self-esteem & High assessment of seif-esteem \\
\hline & $\begin{array}{l}\text { Respondents rate themselves somewhat higher on } \\
\text { positive characteristics (e.g., intelligence, } \\
\text { creativity) than compared to others }\end{array}$ & $\begin{array}{l}\text { Respondents rate themselves much higher on } \\
\text { positive characteristics (e.g., intelligence, } \\
\text { creativity) than compared to others }\end{array}$ \\
\hline & $\begin{array}{l}\text { High ratings of own vulnerability to controllable and } \\
\text { uncontrollable risks }\end{array}$ & $\begin{array}{l}\text { Low ratings of own vulnerability to controllable and } \\
\text { uncontroliable risks }\end{array}$ \\
\hline \multirow[t]{3}{*}{ Effects on information processing } & Open-mindedness to information of all kinds & $\begin{array}{l}\text { Preference for information conducive to the } \\
\text { enactment of an intention }\end{array}$ \\
\hline & $\begin{array}{l}\text { Thoughts tend to focus on "deliberative" behavior } \\
\text { Good recall of others' deliberative behavior }\end{array}$ & $\begin{array}{l}\text { Thoughts tend to focus on "implemental" behavior } \\
\text { Good recall of others' implemental behavior }\end{array}$ \\
\hline & Open-mindedness to incidental information & Attention is centrally focused \\
\hline \multirow[t]{3}{*}{$\begin{array}{l}\text { Effects on optimism/ } \\
\text { pessimism }\end{array}$} & Low feeling of control over uncontrollable events & $\begin{array}{l}\text { Illusionary feeling of control over uncontrollabie } \\
\text { events }\end{array}$ \\
\hline & Realistic view of one's future performance & Optimistic view of one's future performance \\
\hline & $\begin{array}{l}\text { Comparatively negative rating of one's } \\
\text { relationship/partner }\end{array}$ & $\begin{array}{l}\text { Comparatively positive rating of one's } \\
\text { relationship/partner }\end{array}$ \\
\hline Effects on motivation & Lower persistence in putting intentions into practice & Higher persistence in putting intentions into practice \\
\hline
\end{tabular}

personal strengths or weaknesses. The context and commitment to a relationship moderate min'dset effects on people's evaluations of their partners.

\subsubsection{Mindsets and Goal Achievement}

Studies on the effects of deliberative and implemental mindsets on goal achievement supported the hypothesis that the implemental mindset is more conducive to goal attainment than the deliberative mindset, because both information processing and self-evaluation are focused on the task at hand (Section 11.4).

A good predictor of goal attainment in everyday life is persistence of goal-directed behavior, i.e., the tenacity people show in their endeavors to overcome difficulties and master challenges. Accordingly, some authors have investigated the effects of the deliberative and implemental mindsets on persistence of goal striving. Findings presented by PösI (1994) and Brandstätter and Frank (2002) suggest that people in the implemental mindset show greater persistence when faced with difficult tasks. For example, Brandstätter and Frank (2002, Study 1) found that participants in the implemental mindset persisted longer at a difficult puzzle than did participants in the deliberative mindset.

The findings presented by Pösl (1994) paint a differentiated picture. When both the perceived feasibility of the goaldirected behavior and the perceived desirability of the goal were either high or low, the persistence of goal striving was not influenced by the mindset induced. However, when perceived feasibility and desirability were in opposition (i.e., one was high and the other low), participants in the implemental mindset showed greater persistence in goal-directed behavior than did participants in the deliberative mindset. Importantly, moreover, the persistence of goal-directed behavior associated with the implemental mindset is not rigid and inflexible. Brandstätter and Frank (2002, Study 2) observed that as soon as a task is perceived to be impossible, or persistence in what was assumed to be goal-directed behavior proves to be aversive, individuals in the implemental mindset are quicker to disengage from goal pursuit than are individuals in deliberative mindset. Thus, the persistence instigated by the implemental mindset seims to be flexible and adaptive.

With respect to the effectiveness of goal striving in the implemental and deliberative mindsets, experimental findings reported by Armor and Taylor (2003) indicate that implemental mindsets are associated with better task performance than deliberative mindsets, and that this effect. is mediated by the cognitive orientation of the implemental mindset, e.g., enhanced self-efficacy, optimistic outcome expectations, etc. (Section 11.4.4).

(1) The implemental mindset is more conducive to goal striving than the deliberative mindset.

All effects of deliberative and implemental mindsets identified to date are documented in Table 11.2.

\subsubsection{Concluding Discussion: Mindsets and Seir-Feguiacion of Goai Striving}

The findings presented above raise questions about the selfregulation of goal striving. Can people intentionally induce a certain mindset in order to increase their prospects of reaching a certain goal, or to facilitate disengagement from a goal, should it prove unrealistic or undesirable? The implemental mindset has proved particularly effective for promoting goal striving (Section 11.4.6). In the study by Armor and Taylor (2003) mentioned above, the optimistic assessments of 
goal success associated with the implemental mindset led to more effective self-regulation of goal striving and to better outcomes on an achievement-related task than the less optimistic expectations associated with the deliberative mindset. Likewise, Pösl (1994) and Brandstätter and Frank (2002, Studies $I$ and 2) showed that induction of an implemental mindset increased the likelihood of goal attainment; this effect seems to be primarily attributable to the greater persistence in goal striving associated with the implemental mindset.

In any discussion of the relationship between the implemental mindset and goal realization, it is important not to forget that the positive effects of this mindset apply primarily to tasks conducted immediately after it has been induced. The more time elapses between the induction of the implemental mindset and task performance, the less pronounced its positive effects on goal attainment, as Gagné and Lydon (2001a) and Puca (2001) have shown.

\section{SUMMARY}

Critically, the induction of a mindset does not have a permanent influence on information processing and selfevaluation; the effects of the deliberative and implemental mindsets only apply for a certain time.

11.5 Different Kinds of Intentions: Goal Intentions and Implementation Intentions

Both scientific psychology and naive everyday theories often advocate goal setting as a good strategy for enacting wishes and meeting demands. Yet numerous studies have shown that goal setting alone does not guarantee the accomplishment of those goals - even highly motivated people often find it difficult to translate their goals into action. Sometimes they are simply hesitant to actually take action to achieve their goals, and do not initiate goal-directed behavior for this reason. Sometimes they strive for too many, often competing, goals at the same time, including long-term projects that call for repeated efforts over extended periods. Sometimes the situational conditions are not conducive to goal attainment. For example, someone whose attention is focused on intensive emotional experiences will be distracted and may thus fail to register an opportunity to act on his or her goals.

- Contrary to the widespread notion that goal setting is a sufficient condition for the accomplishment of personal goals and projects, an extensive body of research shows that many goals are never actually put into practice.

Drawing on the work of Narziss Ach $(1905,1910,1935)$ and Kurt Lewin (1926b), Gollwitzer (1993, 1999) addressed the difficulties of translating goals into action from the perspective of self-regulation. Gollwitzer concluded that goais can often only be attained when goal pursuit is supported by the selfregulatory strategy of planning. Planning is understood to be the mental anticipation of goal achievement. Against this background, two types of intention are distinguished:

goal intentions and

: implementation intentions.

The concept of "goal intentions" has much in common with Lewin's (1926b) conceptualization of intentions.

Q Gealintentions_specify desired end states that havenotyet been attained. Hence, goal intentions are "goals" in the conventional sense.

Examples of goal intentions are: "I intend to be a good psychologist" or "I intend to be friendly to a certain person."

(1) Implementation intentions are subordinated to goal intentions; they are plans that promote the attainment of goal intentions. In forming implementation intentions, individuals specify the anticipated situations or conditions that will trigger a certain goal-directed response (see the example below). Implementation intentions have the structure "When (if) situation $X$ arises, (then) I will perform response $Y$," and are often called if-then plans.

\section{EWMTLE}

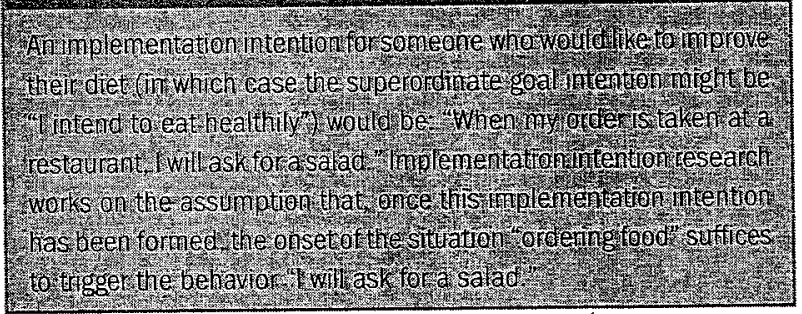

How, then, do implementation intentions differ from habits? In both cases, behavior associated with a certain situation or stimulus is initiated automatically as soon as that situation or stimulus is encountered.

(1) implementation intentions differ from habits to the extent that they originate from a single act of will: the conscious pairing of a desired goal-directed behavior with a critical situation or stimulus. By contrast, habits are formed by the repeated and consistent selection of a certain course of action in a specific situation (cf. Fitts \& Posner, 1967; Newell \& Rosenbloom, 1981).

\subsubsection{How Do Implementation Intentions Work?}

Numerous studies have investigated the psychological processes underlying the effects of implementation intentions. The focus of research has been on the chronic activation of the situation specified in the implementation intention and on the automatic initiation of the action specified. 
The Situation Specified: Chronic Activation

Because forming an implementation intention implies the conscious selection of a critical situation or stimulus as the if-part of the implementation intention, the mental representation of this situation is assumed to be highly activated and thus easily accessible (Gollwitzer, 1999; Gollwitzer, Bayer, \& McCulloch, 2003). This heightened cognitive accessibility makes it easier for people to detect and attend to the critical situation in the surrounding environment, even when they are busy with other things. At the same time, it facilitates recall of the critical situation in terms of how, where, and when the goal-directed behavior is to be enacted. Furthermore, speed of perception differs: critical situations are perceived more quickly than situations not specified in implementation intentions. A classic cognitive accessibility study is described below.

\section{STUDY}

\section{Classic Study on the Cognitive Accessibility of} Situations Specified in Implementation Intentions Findings from a dichotic listening experiment show that words describing the anticipated critical situation are highly disruptive to focused attention. Mertin (1994) presented participants with words to both ears simultaneously via headphones. Participants were instructed to "shadow" the words presented on one channel, i.e., to repeat these words as soon as they heard them, and to ignore the words presented on the other channel. Attention was thus focused on one channel. It emerged that participants' shadowing performance was much slower when words relating to the critical situation were presented to the nonattended channel than when unrelated words were presented. In other words, critical words attracted attention, even when efforts were made to direct attention to the shadowing task. The same effect was not observed either in a group of participants who had only formulated a goal intention without furnishing it with implementation intentions, or in a group who had not formulated any intentions at all on how to approach the task at hand.

This finding indicates that the critical situations specified in implementation intentions are unlikely to escape people's attention, even when they are busy with other things.

The findings of a study using the Embedded Figures Test (Gottschaldt, 1926) provide further evidence for the enhanced cognitive accessibility of the critical situation. The objective of this-test-is-to-detect smailer " $a$-figures" thiat are concealed within larger " $b$-figures." Participants who had specified the " $a$-figure" in the if-part of an implementation intention were better able to detect these hidden figures than participants who had only formulated a goal intention (Steller, 1992).

In a cued recall experiment, participants had to decide when, where, and how to play certain games by choosing between a number of set options offered by the experimenter. In a surprise memory test administered bothimmediatelyand
48 hours later, participants who had specified their choices in an implementation intention recalled these options much more effectively than participants who had formulated goal intentions only (Gollwitzer et al., 2002).

Finally, Aarts, Dijksterhuis, and Midden (1999), using a lexical decision task, provided further support for the assumption that implementation intentions lead to heightened activation of specified situational cues. Participants who had specified critical cues in implementation intentions showed faster lexical decision responses than did participants who had only formed goal intentions.

(1) The chronic activation of the situation specified in the implementation intention is thus reflected in its heightened cognitive accessibility, which in turn facilitates effectively detecting, readily attending to, and successfully remembering critical situational cues.

\section{Implementation Intentions and Action Initiation}

As mentioned above, action initiation becomes automatic once an implementation intention has been formulated through a single act of will. In forming implementation intentions, individuals can strategically switch between the conscious and effortful control of goal-directed behaviors and the automatic control of these behaviors in response to selected situational cues. Gollwitzer et al. (2002; e.g., Gollwitzer \& Schaal, 1998; Gollwitzer, Fujita, \& Oettingen, 2004) call this type of automatic action control strategic automaticity. The goal-directed behavior specified in the implementation intention is assumed to be triggered immediately, efficiently, and without conscious intent whenever the critical situation is encountered. Thus, someone who has formed an implementation intention does $r \mathrm{st}$ have to invest cognitive resources in conscious and effortful control of the goaldirected behaviors specified in an implementation intention; rather, their performance is placed under the direct control of situational cues.

Implementation intentions are thus more effective than goal intentions alone in various respects. For example, it has been shown that participants who have formed implementation intentions respond to the critical situation immediately, even at high levels of distraction. The findings of dual-task experiments attest to the efficiency of automatic action initiation in this context (Brandstätter, Lengfelder, \& Gollwitzer, 2001; Achtziger, Michalski, \& Gollwitzer, forthcoming). Participants in these experiments have to perform two tasks at the same time. A decrease in performance on one task is interpreted as indicating that the other task taxes cognitive resources. A series of studies using this dual-task paradigm have shown that cognitive resources are not required to initiate the responses induced by implementation intentions. For example, two experiments by Brandstätter et al. (2001, Studies 3 and 4) showed that students working on a task that required them to press the response button as soon as a particular stimuli appeared on the computer screen responded 


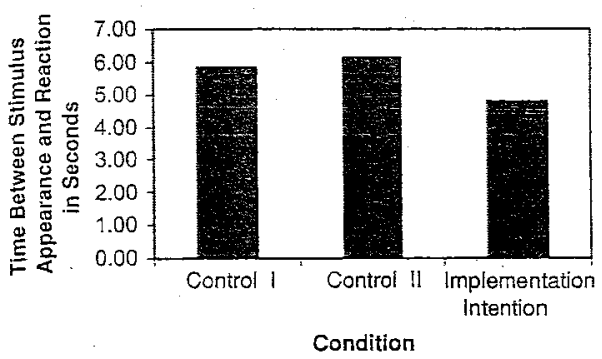

Figure 11.2 Reaction times in a dual-task experiment with and without implementation intentions (Brandstatter, Lengfeider, \& Göllwizer, 2001)

substantially faster if they had formed an implementation intention, even when a dual task had to be performed at the same time. Students who had only formed a goal intention to respond as quickly as possible did not show enhanced reaction times under the dual-task condition. The results of this study are presented in Fig. 11.2.

STUdies WITH CLINICAL SAMPLES. In further studies, Brandstätter et al. (2001) showed that even patients who have severe problems with action control from chronic cognitive load can benefit from implementatinn intentions. For example, drug addicts under withdrawal benefited from forming implementation intentions specifying when and where to perform actions that would facilitate their return to "normal" life. Most implementation intention patients succeeded in writing a curriculum vitae to be used in job applications before a set deadline, whereas goal intention participants missed the deadline. In other words, the chronic cognitive load associated with withdrawal did not inhibit goal-directed behavior if an implementation intention had been formed.

Lengfelder and Gollwitzer (2001) tested the hypothesis that implementation intentions automate action initiation in studies with frontal lobe patients. Individuals with frontal Iobe injury typically have problems with the conscious control of automated actions or habits. Whenever they see a pair of scissors, for example, they will reach for the scissors and begin cutting, and are not able to consciously and deliberately interrupt that action, no matter how hard they try. In other words, a stimulus associated with the execution of a particular action will involuntarily and inevitably trigger that action in these patients. Against this background, Lengfelder and Gollwitzer (2001) administered a go/no-go task to frontal lobe patients. In this type of task, participants have to respond to selected stimuli (e.g., to press a button when two of five visual patterns appear on a computer screen), but not to others (i.e., selective attention). If implementation intentions are indeed based on automatic processes, as assumed by Lengfelder and Gollwitzer (2001), the patient group should show faster reaction times to the situational cues specified in an implementation intention in the go/no-go task than a control group of healthy individuals. This prediction was con- firmed, with frontal lobe patients showing significantly faster reaction times than the control group.

This finding indicates that the executive functions governed by the frontal lobe are not required in implementation intentions, thus suggesting that implementation intention effects are primarily based on automatic processes.

Further experimental support for this finding has been provided by Achtziger et al. (forthcoming) and Gawrilow and Gollwitzer (2004). Using a procedure that blocks the central executize-ef working-memery (cf. Baddeley, 1996), Achtziger et al. (forthcoming) were able to show that the performance of participants who had formed an implementation intention to support the processing of stereotype-inconsistent information about a target person did not differ depending on whether or not the functions of the central executive had been blocked. However, participants who had not formed an implementation intention proved unable to process stereotype-inconsistent information when the central executive was blocked, and therefore judged the target person in a stereotypical manner. Blocking the central executive puts a heavy load on the frontal lobes (Baddeley, 1996), meaning that automatic processes take precedence. The finding that implementation intentions take effect even when the central executive of working memory is blocked confirms that implementation intention effects do not tax cognitive resources.

Gawrilow and Gollwitzer (2004) demonstrated the effects of implementation intentions in a group of children diagnosed with attention deficit hyperactivity disorder (ADHD). Children with $A D H D$ are known to have important deficits in executive functioning and hence in processes that tax cognitive resources. They consequentiy find it very difficult to respond quickly and reliably to stop signals. Before being administered a variation of the stop task (cf. Logan, Schachar, \& Tannock, 1997), children with ADHD were asked to formulate an implementation intention specifying that they would stop what they were doing as soon as they encountered a certain stimulus. Findings showed that, having formulated this implementation intention, $\mathrm{ADHD}$ children managed to inhibit the behavior in question just as well as a control group of healthy children. Thus, the study provided further evidence that implementation intention effects are primarily based on automatic processes, and not on processes that involve central executive functions, and hence tax cognitive resources.

Gollwitzer and Brandstätter (1997, Study 3) demonstrated the immediacy of action initiation as soon as the critical situation is encountered. One group of participants formed implementation intentions that specified viable opportunities for presenting counterarguments to a series of racist remarks made by a confederate of the experimenter; another group formulated goalintentions to the same effect. As expected, the implementation intention participants initiated their counterarguments to the racist comments more quickly, than 
did the goal intention only participants. The study presented: below provided empirical evidence that implementation intentions lead to action initiation even in the absence of conscious intent.

\section{STUDY}

Study on Action Initiation in the Absence of Conscious Intent

Bayer, Achtziger, Malzacher, Moskowitz, and Gollwitzer (forthcoming) conducted two experiments to test whether implementation intentions lead to action initiation without conscious intent once the critical situation is encountered. In these experiments, the critical situation was presented subliminally (i.e., below the threshold for perception).

In Study 1, Bayer and colleagues investigated whether participants were able to achieve their goal of asserting themselves against a rude experimenter by formulating an implementation intention. Half of the participants were encouraged to set the goal of reprimanding the experimenter by drawing attention to her rude behavior (goal intention condition); the other half were additionally instructed to plan to take this action as soon as they set eyes on her (implementation intention condition). Afterwards, faces of either the experimenter who had showed the rude behavior or a neutral, unknown person were presented subliminally (as primes) to all participants by means of a tachistoscope (presentation times of less than $10 \mathrm{~ms}$ ). Primes are stimuli that serve to activate associated cognitive contents. These cognitive contents are presented subsequent to the primes and their effects are measured, usually in terms of reaction times. Immediately after each prime, participants were presented with certain words, some of which were associated with rudeness (e.g., offensive, aggressive, arrogant). Participants were asked to repeat all of the words as quickly as possible, and the latencies of their responses were measured by the computer. After the subliminal presentation of the critical primes, participants who had formed an implementation intention to reprimand the experimenter as soon as they set eyes on her showed faster response times to words related to rudeness than did participants who had only formed goal intentions.

This finding provides further confirmation that the goal-directed behavior specified in implementation intentions is initiated automatically - i.e., triggered immediately, efficiently, and without conscious intent - as soon as the critical situation is encountered.

THE ROLE OF COMMITMENT IN IMPLEMENTATION INTEN TION EFFECTS. Might the effects of implementation intentions be attributable in part or even wholly to an associated increase in goal commitment? If furnishing goals with implementation intentions indeed produces an increase in the level of commitment to superordinate goal intentions, the assumption that implementation intentions automatize the initiation of goal-directed behavior and other cognitive processes would be immaterial. However, this hypothesis has not received any empirical support. For example, Brandstätter et al. (2001, Study 1 ) found that the positive effect of an imple- mentation intention to submit a curriculum vitae before a specified deadline was independent of the patients' general commitment to writing a curriculum vitae. Patients in the implementation intention group were no more committed to the goal than were patients in the goal intention group. Analogous results have been reported in numerous studies from domains such as disease prevention (e.g., Orbell, Hodgkins, \& Sheeran, 1997), social impression formation (Seifert, 2001, Studies $I$ and 2; Achtziger, 2003, Studies 1 and 2), and tennis competitions (Achtziger, Gollwitzer, \& Sheeran, in press, Study 2).

All mechanisms known to underlie the effects of implementation intentions are listed in the following overview.

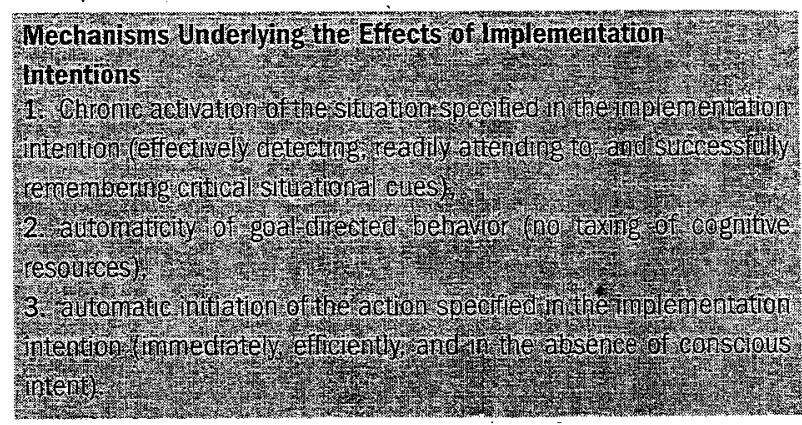

\subsubsection{Implementation Intentions and the Initiation} of Wanted Behavior

Because implementation intentions facilitate attending to detecting, and remembering situations conducive to goaldirected behavior and, in addition, help to automatize action initiation, people who form implementation intentions can be expected to show higher goal-attainment rates than people who do not furnish their goal intentions with implementation intentions. The results of a host of studies in very different domains provide empirical support for this hypothesis.

Effects of Implementation Intentions on Achievementand Health-Related Behavior

Research on implementation intentions tends to examine goal intentions that are difficult to attain for reasons already mentioned; e.g., because of external or internal distractions or because the action required is unpleasant or painful. For example, Gollwitzer and Brandstätter (1997) analyzed a goal intention that had to be performed during the Christmas vacation. Students were given the task of writing a report about Christmas Eve no later than 48 hours after the event. As expected, students who had formed a corresponding implementation intention were significantly more likely to write a report within the allotted time than students who had only formed a goal intention.

Orbell, Hodginks, and Sheeran (1997) found that women who had set themselves the goal of performing regular breast self-examinations greatly benefited from forming implementation intentions. Similar patterns of results have 
emerged for parücipation in voluntary cancer screening (Sheeran \& Orbell, 2000), resumption of functional activity after hip replacement surgery (Orbell \& Sheeran, 2000), and engagement in physical exercise (Milne, Orbell, \& Sheeran, 2002). Furthermore, implementation intentions have been found to facilitate the attainment of goal intentions that are otherwise easily forgotten; e.g., regular intake of vitamin tablets (Sheeran \& Orbell, 1999) or signing each page of an intelligence test (Chasteen, Park, \& Schwarz, 2001).

\section{Significant Moderatcrs of Implementation Intention Effects}

The strength of implementation intention effects depends on the presence or absence of various moderators. Some studies (e.g., Gollwitzer \& Brandstätter, 1997, Study 1)' show that the more difficult it is to initiate a goal-directed behavior, the more pronounced implementation intention effects become. The findings of the study with frontal lobe patients described above (Lengfelder \& Gollwitzer, 2001, Study 2; Section. 11.5.1) are relevant here as well. Patients with a frontal lobe injury typically have problems with the conscious control of behavior because their access to executive functions and cognitive resources is limited. Findings show that patients who formed an implementation intention in preparation for a reaction time task outperformed a sample of college students who had formed the same implementation intention. Because the reaction time task can be assumed to be more difficult for the patients than for the healthy students, this finding confirms that forming implementation intentions is particularly beneficial to people faced with difficult tasks.

- Commitment to the goal intention also seems to moderate the effects of implementation intentions. Orbell et al. (1997) report that implementation intentions only enhanced compliance in performing breast self-examinations in women who strongly intended to examine their breasts, i.e., who were committed to the superordinate goal intention. Similarly, Gollwitzer et al. (2002, Study 3) found that beneficial effects of implementation intentions on participants' recall of critical situations were only observed when the goal intention had yet to be translated into reality. If it had already been accomplished, no implementation intention effect on memory performance was detected. Furthermore, Sheeran, Webb, and Gollwitzer (2005, Study 1) showed that the beneficial effects of implementation intentions concerning the goal of preparing for an upcoming exam increased as a function of the amount of studying required. In addition to strength of commitment to the goal intention, commitment to the specific implementation intention is required. In the memory study by Gollwitzer et al: (2002), the strength of the commitment to the implementation intention was varied by telling participants (after administering a battery of personality tests) that they were the type of person who would benefit either from strictly adhering to their plans (high commitment condition) or from staying flexible (low commitment condi- implementation intention effects than those in the former group.

Sheeran et al. (2005, Study 2) found that implementation intention effects only occur when the respective superordinate goal intention is activated. The implementation intention to move on to the next item in an intelligence test immediately after finishing the previous one enhanced speed of task processing only when the goal intention of working as quickly as possible was activated. Likewise, in an experiment using the Rogers and Monsell (1995) task-switch paradigm, Bayer, Jauuas, arid Gollwitzer (2002) found that impiementation intention effects are dependent on the superordinate goal being activated.

Finally, it can be assumed that the strength of the mental link between the if- and then-parts of an implementation intention moderates its effects. For example, if a person invests a lot of time and concentration in encoding an implementation intention in long-term memory and/or mentally rehearsing that intention, stronger mental links should be forged between the two parts, which should in turn produce stronger implementation intention effects. This assumption has not yet been subjected to experimental testing, however.

\section{SUMMARY}

The difficulty of initiating goal-directed behavior, the strength of commitment to goal intentions and implementation intentions, and the activation of the goal intention have proved to be significant moderators of implementation intention effects.

\subsection{Implementation Intentions and the Control of Unwanted Behavior}

To date, research has focused almost exclusively on how implementation intentions can help to translate goals into action by facilitating wanted, goal-directed behavior, and particularly the initiation of goal-directed behavior. Yet merely initiating goal pursuit rarely suffices to achieve a goal. Once initiated, a process of goal striving ha to be maintained. People need to shield their goals from distractions or conflicting bad habits. Ways in which implementation intentions can be used to control these "unwanted" effects are outlined below.

Unwanted responses that hamper the successful pursuit of goals can be controlled by different types of implementation intentions. For example, someone who wants to avoid being unfriendly to a friend who is known to make outrageous requests can protect herself from showing the unwanted response by forming the goal intention "I intend to stay friendly" and furnishing it with one of the following three suppression-oriented implementation intentions:

lst suppression-oriented implementation intention: "And if my friend makes an outrageous request, then I will not respond in an unfriendly manner." The strategy here is 
the critical situation in the if-part of the implementation intention, and ruling out the unwanted response in the then-part. Alternatively, the focus may be on facilitating the initiation of a wanted response:

- 2nd suppression-oriented implementation intention: "And if my friend makes an outrageous request, then I will respond in a friendly manner." In this case, the critical situation is again specified in the if-part, and the wanted response that is threatened by disruptive unwanted responses is endorsed in the then-part.

3rd suppression-oriented implementation intention: "And if my friend makes an outrageous request, then I will ignore it." In this variant, the critical situation is again specified in the if-part of the implementation intention, and the then-part focuses the person away from the critical situation.

Gollwitzer and colleagues have conducted a series of studies using these three types of suppression-oriented implementation intentions. Most of these studies investigated the control of unwanted spontaneous responses to distractions or of automatic activation of stereotypes and prejudice.

\subsubsection{Suppression-Oriented Implementation Intentions}

When goal pursuit is threatened by distracting stimuli, implementation intentions should be formed to inhibit those distractions, as illustrated by the study described below.

\section{STUDY}

\section{Implementation Intentions and Resistance}

\section{to Distractions}

in a computer-based experiment (Gollwitzer \& Schaal, 1998) college students performed a series of arithmetic problems while distracting clips of popular commercials were shown at random intervals on a TV screen mounted above the computer monitor. Findings showed that goal intentions ("I will not let myself get distracted") were less effective in protecting participants from the distractions of the commercials than were implementation intentions. Moreover, implementation intentions phrased as distraction-inhibiting ("And if a distraction arises, then I will ignore it") produced better results than those phrased as task-facilitating ("And if a distraction arises, then I will focus my attention on the arithmetic tasks"). Specifically, distraction-inhibiting implementation intentions helped participants to ward off the distractions of the commercials regardless of their motivation to do the tedious arithmetic problems, whereas task-facilitating implementation intentions were effective only when motivation to do the problems was low. When motivation was high, task-facilitating implementation intentions did not shield participants against the distractions of the commercials, and performance on the arithmetic tasks was poor. These findings suggest that taskfacilitating implementation intentions may result in overmotivation in distracting conditions and thus undermine performance.
CONTROLLING PREJUDICE. Researchers have also investigated the function of implementation intentions as strategies for controlling unwanted stereotypes in impression formation. In general, models of impression formation (e.g., Brewer, 1988; Devine, 1989) assume that the effects of social stereotypes and prejudices on the way people judge others are governed by processes that require attention, cognitive resources, and conscious effort. Until recently, stereotype research assumed that the application of stereotypes-butnot their activation - can be intentionally controlled (cf. Brewer, 1988; Devine, 1989). Stereotype activation was thought to be an unavoidable, automatic process; stereotype use, to be controllable by effortful correctional strategies. Based on the studies of the automaticity of impiementation intentions described above, Gollwitzer's research group conducted a series of experiments to test whether implementation intentions can inhibit the automatic activation of stereotypes and prejudice, and not just their application. The assumption was that an automatic process such as the activation of a stereotype can be blocked by other automatic processes such as those triggered by implementation intentions. Experiments using different priming paradigms showed that the automatic activation of the stereotype "old person" was inhibited when participants formed an implementation intention ("When I see an old person, then I will tell myself: don't stereotype!"), but was still observed in a group of participants who had formed a goal intention only ("I intend to judge fairly") and in a control group who were simply instructed to form an impression of the people presented (Gollwitzer, Achtziger, \& Schaal, forthcoming). Analogous results emerged from a study in which male participants were asked to inhibit the stereotype "women," and studies in which participants of both sexes were asked to inhibit the stereotypes "homeless person" or "soccer fans" (Achtziger \& Gollwitzer, 2005).

Other studies investigated the extent to which implementation intentions can prevent the application of stereotypes. Seifert (2001, Study 1) tested whether the discrimination of female job seekers applying for jobs in technical domains can be controlled by implementation intentions. Computer science students were presented with a number of applications for the position of computer scientist and a profile of the job's requirements. Half the fictional applicants had a woman's name, the other half a man's name. In a preliminary study, in which all applicants had male names, all applicants were judged to be equally qualified for the job. When male and female names were assigned to the applications at random, however, the computer science students were considerably more likely to hire male candidates, thus discriminating against the female candidates. Only a group of students who had formed the implementation intention "When I evaluate an application, then I will ignore the candidate's gender" managed to overcome this bias. Stereotype research has evidenced that individuals under cognitive load are unable to process 
stereotype-inconsistent information about unknown others (cf. Macrae, Hewstone, \& Griffiths, 1993). Stereotypeinconsistent information is not generally attributed to representatives of certain social categories. For example, "machos" are not usually characterized as "tolerant." Successful processing of stereotype-inconsistent information results in nonstereotypical impressions. In two studies, Achtziger et al. (forthcoming) replicated the finding that stereotypeinconsistent information is poorly processed under cognitive load, and showed that people who formed implementation -intentions are able to process sterestype-incensistentinformation and hence to evaluate others fairly, even under cognitive load.

SUPPRESSION OF EMOTIONAL RESPONSES. Research has shown that, apart from regulating unwanted behavioral responses (e.g., to distractions) and precluding unfair evaluations of others, implementation intentions can also inhibit -unwanted emotional responses. For example, Schweiger Gallo, Achtziger, and Gollwitzer (2003) report a study examining how implementation intentions can be used to inhibit disgust. Female participants were presented with picture cues from the International Affective Picture System (IAPS; CSEA, 1999). Some of these pictures show photographs of injured and mutilated individuals, and activate the emotion "disgust." Participants were able to suppress their disgust by means of an implementation intention, but not by means of a goal intention alone.

\section{SUMMARY}

Suppression-oriented implementation intentions have proved effective in inhibiting spontaneous attentional responses, stereotypical and prejudicial responses, and reflexive negative emotional responses.

\subsubsection{Blocking Detrimental Self-States by Planning Wanted Behavior}

In the research presented in Section 11.6.1, the critical situation specified in the if-part of an implementation intention was linked to a then-part that served to suppress unwanted responses. Implementation intentions may also protect against unwanted responses in another way, however. Instead of focusing on anticipated obstacles and the unwanted responses they trigger, implementation intentions may be designed to stabilize an ongoing goal pursuit. For example, an exchange of opinions can soon develop into an argument if the parties are tired and worn out, even if they did not intend the situation to escalate. However, if the parties planned in advance how to respond constructively to conflicting opinions, the self-states of fatigue and exhaustion should not have a negative impact on the discussion. These assumptions have been tested in a series of studies, one of which is described below.

\section{SIOI?}

\section{Study on Blocking Negative Self-States}

One of the studies on the use of implementation intentions to block negative self-states (Gollwitzer \& Bayer, 2000, Study 1) was based on the theory of symbolic self-completion (Wicklund \& Gollwitzer, 1982) and tested the extent to which the negative effects of selfdefinitional incompleteness on social sensitivity (cf. Gollwitzer \& Wicklund, 1985a) can be attenuated by forming implementation intentions. Participants were law students who were highiy committed to becoming.successfullawyers. As a cover story, they were-nild that the study had been designed to analyze how goals affect how people get to know each other. To this end, they would be introduced to another student; their goal was to take that person's perspective during the conversation. Half of the participants were instructed to furnish this goal with the following implementation. intention: "And if my partner expresses a preference for a certain topic of conversation, then i will direct the conversation to that topic." They were then administered a questionnaire on how they approached their studies ("no sense of incompleteness" condition) or the same questionnaire with three supplementary questions'drawing attention to shortcomings in their current skills and experience (e.g., "Do you have courtroom experience as a judge or district attorney?"). This second questionnaire was designed to create a sense of selfdefinitional incompleteness.

Finally, all participants were informed that the person they were to meet was called Nadia, and that she had already indicated her preferences for potential topics of conversation. Participants were then handed a sheet of paper listing these preferences. It was quite clear that Nadia did not want to discuss law, but would prefer to talk about her last vacation and popular movies. To assess whether self-definitional concerns would increase the likelihood of participants' choosing law as a preferred topic of conversation despite Nadia's preferences, all participants were asked to note down their own preferred topics for Nadia. In the control condition, a self-completion effect was clearly apparent: participants with an incomplete self-definition were more likely to want to talk about law than participants with a complete self-definition, even though Nadia was clearly not interested in discussing this topic. The same effect was not observed in the group of participants who had formed an implementation intention, however - these participants showed the same low preference for law as a potential conversation topic, whether their self-definitions were complete or incomplete.

These findings show that implementation intentions are able to block the negative effects of the self-state "self-definitional incompleteness” on goal-directed action (specifically, taking someone else's perspective).

\section{Implementation Intentions and Self-Regulatory}

\section{Performance}

According to ego-depletion theory (Baumeister, 2000; Muraven, Tice, \& Baumeister, 1998), performing a task that demands a high level of self-regulation will encroach on performance on a second task that also requires 
self-regulation. Gollwitzer and Bayer (2000, Study 3) were interested in whether this effect could be countered by implementation intentions. In a classic ego-depletion paradigm, participants were first shown a humorous movie and instructed either to express their emotions freely, or to show no emotions at all. They were then presented with a number of difficult anagrams. All participants had formed the goal intention to solve as many anagrams as possible. Half the participants had furnished this goal intention with an implementation intention: "And if $I$ have solved one anagram, then I will move on immediately to the next." Participants who had only formed a goal intention showed the classic ego-depletion effect, with those who had been instructed not to show their emotions during the film performing less well on the anagram task than those who had given free rein to their emotions. This effect was not observed in participants who had furnished the goal intention to perform well with an implementation intention, however.

Webb and Sheeran (2003, Study 2) also demonstrated that implementation intentions can offset ego-depletion effects. First, half the participants were instructed to balance on their "weaker" leg while counting down in sevens from"1,000 (egodepletion manipulation). Participants in the control condition counted to 1,000 in fives while standing normally on two legs. All participants were then given the goal intention of naming the ink color of words presented in a Stroop test as quickly as possible. Half the participants furnished this goal intention with an implementation intention: "When I see a word, then I will ignore its meaning and name the color in which it is printed." No ego-depletion effect was observed for implementation intention participants; those who had been ego-depleted in the initial task performed as well in the Stroop test as those in the nondepleted control condition. However, participants who had only formed a goal intention showed a marked ego-depletion effect, with those who had been egodepleted scoring notably lower on the Stroop task than their nondepleted counterparts.

\section{SUMMARY}

The negative effects of both self-definitional incompleteness and ego-depletion can be blocked by forming implementation intentions.

\subsubsection{Blocking Adverse Contextual Influences by Planning Wanted Behavior}

People may see the outcomes of their actions in terms of gains or of losses (Kahneman \& Tversky, 1979). Conflict-resolution research suggests that cognitive processes triggered by "loss framing" or "gain framing" have a strong impact on negotiation processes and their outcomes (De Dreu et al., 1994). Loss framing results in comparatively unfair agreements and other negative effects. Trötschel and Gollwitzer (2004) investigated whether these negative loss framing effects can be over- come if prosocial goals, such as finding a fair or integrative solution, are furnished with corresponding implementation intentions. This hypothesis was tested in two experiments, the first of which is described below.

\section{STUDY}

Overcoming Loss Framing Effects by Means of Implementation Intentions

Pairs of participants were assigned the roles of heads of state of two rival countries and asked to negotiate the partitioning of a disputed island. The island was made up of 25 regions, each representing one of four terrains: mountains, cornfields, pastures, or forests. Within each pair of negotiators, one participant was subjected to loss framing as foilows:

- Loss framing condition: The participant was handed a table listing the four different types of regions, and specifying the loss that would be incurred if each were relinquished to the other participant in terms of a negative score. The other participant in each pair of negotiators was subjected to gain framing.

Gain framing condition: In this condition, the regions listed in the table were allocated positive scores, indicating the gain that would be incurred if that region were appropriated.

Both participants were told that they had to come to an agreement on the distribution of the 25 regions within 15 minutes. A faimess. goal was instilled in some participants by handing them a sheet of paper informing them that fair negotiation outcomes are often. very difficult to achieve, and instructing them to set themselves the following goal shortly before entering the negotiations: "I want to find a fair solution." Half the participants with a fairness goal were additionally instructed to furnish this goal intention with an implementation intention: "And if my opponent makes a proposal, then I will make a fair counterproposal." Participants in the control condition were not instructed to specify either a fairness goal or an implementation intention. Outcomes were assessed in terms of individual "profits" within each pair of negotiators. in each of the three conditions, the authors tested whether the difference in profits within each dyad was significantly different from zero.

in both the goal intention condition and the control condition significant differences in profits were observed as a function of the framing condition. Participants who had been subjected to loss framing made higher profits than those subjected to gain framing. Unfair outcomes of this kind were not observed in the implementation intention condition, where profits were equally distributed between paricipants.

\section{Intentions and Performance Feedback}

Goal attainment can also be negatively affected by unfavorable performance feedback conditions. One example here is the "social loafing" phenomenon often observed at workplaces where employees are given collective, rather than individual performance feedback (cf. Latané, Williams, \& Farkins, 1979; Karau \& Williams, 1993): people when working 
in groups where individual performance cannot be monitored have been observed to show lower performance levels. Gollwitzer and Bayer (2000, Study 4) tested whether this phenomenon can be counteracted by means of implementation intentions. Their participants were asked to generate as many uses as possible for a common knife under one of two conditions:

"Collective performance feedback" condition: Participants were told that their responses would be pooled with those of seven other participants, and that the experimenter would not-be-able to-tell hort-many-uses each individual had generated.

.. "Individual performance feedback" condition: Participants were told that the experimenter would be able to assess each participant's performance separately.

Before beginning the task, all participants formed the goal intention "I intend to name as many uses as possible." Half of the participants furnished this goal intention with the implementation intention: "And when I have noted down a use, then I willimmediately go on to the next." The number of uses generated in 12 minutes was taken as the dependent variable. Goal intention participants generated notably fewer uses in the "collective performance feedback" condition than in the "individual performance feedback" condition. This pattern of results, which replicates the classic social loafing effect, was not observed in implementation intention participants, who generated an equal volume of responses, regardless of the feedback condition.

\section{Formation of Implementation Intentions and Competing Goals}

Auto-motive theory (Bargh, 1990; Bargh \& Gollwitzer, 1994) holds that when goal striving is activated repeatedly and consistently in response to a given situation, this situation will eventually acquire the potential to trigger the critical goal pursuit without conscious intent (Bargh, 1990; Bargh \& Gollwitzer, 1994). A goal intention that can be activated in this way is called a "chronic goal." Gollwitzer (1998) conducted two experiments to test whether implementation intentions can shield ongoing goal pursuit against the effects of directly activated chronic goals.

In the first study, participants had to navigate a car along a race track in a simulator. The mean driving speed and number of errors were measured in two baseline circuits. Participants were then given precise instructions on how to drive the next two circuits.

( Participants in the goal intention condition were instructed to set themselves the goal of reaching the finishing post as quickly and with as few errors as possible.

- Participants in the implementation intention condition were additionally instructed to form the following implementation intentions: "And when I enter a curve, then I will reduce my speed. And when I enter a straight section of the track, then I will speed up again."
Before participants were allowed to drive the final two circuits of the track, auto-motive priming was used to activate two goals beyond the participants' conscious awareness. All participants were asked to join the numbered dots presented on different sheets of paper as quickly as possible to produce various shapes (flowers, animals, and other objects). Those in the "move quickly" priming condition were instructed to complete as many figures as possible in five minutes. Those in the "move slowly" priming condition were told to join the dots as carefully and neatly as possible, taling as much time as they needed for each-shape. Findings showed that this auto-motive priming had pronounced effects on goal intention participants' driving in the last two circuits: those in the "move quickly" condition drove faster and made more mistakes than those in the "move slowly" condition. No such priming effect was observed for implementation intentions participants, who drove at a moderate speed and made few mistakes in both priming conditions. These findings indicate that goal pursuits furnished with implementation intentions are not affected by competing, nonconscious goals that are activated by situational cues.

Table 11.3 documents all effects of implementation intentions that have been identified to date.

\subsection{Potential Costs of Implementation} Intentions

As we have shown, implementation intentions facilitate goal pursuit in various ways. It seems reasonable to hypothesize that such an effective means of self-regulation may have certain unforeseen costs. This section examines the three following potential costs of implementation intentions:

1. It is possible that implementation intentions lead to a certain rigidity of behavior that may be detrimental when task performance requires high levels of flexibility.

2. It is possible that implementation intentions cause a high degree of ego-depletion and thus undermine selfregulatory resources.

3. It is possible that thoughts, feelings, and actions may resurface later in a different context (rebound effects), although implementation intentions successfully suppresses unwanted thoughts, feelings, and actions in a given context.

\subsubsection{Implementation Intentions and Behavioral Rigidity}

Do people who have formed implementation intentions also recognize alternative opportunities to act toward their goal, or do they insist on acting only when the critical situation specified in the implementation intention is encountered? The strategic automaticity created by implementation 


\begin{tabular}{|c|c|}
\hline Controlling unwanted behavior & Promoting wanted behavior \\
\hline $\begin{array}{l}\text { Suppressing unwarited thoughts, feelings, and actions } \\
\text { ("suppression-oriented implementation intentions") }\end{array}$ & Fostering the initiation and execution of goal-directed actions \\
\hline $\begin{array}{l}\text { Inhibiting automatic activation of stereotypes (e.g., age stereotypes, } \\
\text { gender stereotypes) }\end{array}$ & Increasing the latency of counterarguments to racist remarks \\
\hline $\begin{array}{l}\text { Inhibiting prejudice (e.g., discrimination of women in male-dominated } \\
\text { professions) }\end{array}$ & $\begin{array}{l}\text { Increasing the probability of participation in cancer screening (e.g., } \\
\text { mammography) }\end{array}$ \\
\hline $\begin{array}{l}\text { Shielding against distraction during complex tasks (e.g., distracting } \\
\text { effects of commercials while working on arithmetic probiems) }\end{array}$ & $\begin{array}{l}\text { Facilitating the processing of stereotype-inconsistent information } \\
\text { despite cognitive load (e.g., on the central executive) }\end{array}$ \\
\hline $\begin{array}{l}\text { Controlling impulsive behavior in children with ADHD (e.g., enhancing } \\
\text { resoonse inhibition in a reaction-time task) }\end{array}$ & $\begin{array}{l}\text { Fostering persistence of goal-directed actions } \\
\text { Supporting the regular intake of vitamin tablets and essential }\end{array}$ \\
\hline Replacing unwanted behavior by other behavior & medication \\
\hline $\begin{array}{l}\text { Inhibiting the automatic activation of prejudice (e.g., toward homeless } \\
\text { people) }\end{array}$ & $\begin{array}{l}\text { Helping challenged patient groups to perform difficult everyday actions } \\
\text { (e.g., drug addicts under withdrawal to write a CV) }\end{array}$ \\
\hline Inhibiting negative emotions (e.g., disgust) & Fostering engagement in physical exercise (e.g., after hip replacement \\
\hline $\begin{array}{l}\text { Inhibiting behavior that is detrimental to health (e.g., cigarette and } \\
\text { alcohol consumption) }\end{array}$ & surgery) \\
\hline \multicolumn{2}{|l|}{$\begin{array}{l}\text { Shielding wanted behavior from unwanted internal and } \\
\text { external influences }\end{array}$} \\
\hline \multicolumn{2}{|l|}{$\begin{array}{l}\text { Blocking unfavorable contextual influences (e.g., deindividualization, } \\
\text { competing goal activations, framing effects) }\end{array}$} \\
\hline $\begin{array}{l}\text { Blocking detrimental self-states (e.g., self-definitional incompleteness, } \\
\text { mood, ego-depletion) }\end{array}$ & \\
\hline
\end{tabular}

intentions - i.e., the delegation of behavioral control to situational cues - can be assumed to free up cognitive resources, thus allowing effective processing of information about alternative opportunities. This assumption has been confirmed in a number of studies showing that individuals who had formed an implementation intention were not blind to changed situational contexts or unexpected opportunities to achieve their goal. Instead of sticking rigidly to their plans, participants responded appropriately to new situations.

For instance, Achtziger (2003, Study 2) showed that participants are able to form implementation intentions that are only applied in certain contexts. A study on prejudice toward soccer fans showed that participants were able to apply the implementation intention "And if I see a soccer fan, then I'II not evaluate him negatively" flexibly, dependent on the context. In this study, the presence of a signal tone indicated that the implementation intention should be applied, whereas the absence of the tone indicated that it should not. In line with the assumption that impiementation intentions do not necessarily lead to behavioral rigidity, the inhibition of prejudice.toward "soccer fans" was only observed when pictures of soccer fans were accompanied by a signal tone. Likewise, another study (Jaudas \& Gollwitzer, 2004) showed that participants who encountered an unexpected opportunity to pursue a goal intention -i.e., an opportunity other than the one specified in the if-part of the implementation intention-were able to recognize and seize this new opportunity. Participants were shown two symbols (e.g., flower, heart) on a monitor and asked to select the symbol with the highest score. Before the study began, they had been told the score of each symbol, and some participants had formed the implementation intention to select the symbol with the highest score especially quick by pressing the button as soon as it appeared. After a while, a new symbol with an even higher score was presented on the screen. Participants in the implementation intention condition succeeded in selecting this new symbol rather than the one that previously had the highest score.

\subsubsection{Implementation Intentions and Ego Depletion}

The assumption that implementation intentions automate the control of goal-directed behavior implies efficient and relatively effort-free behavioral control. In other words, the self is not implicated - and should therefore not become depleted - when behavior is controlled by implementation intentions. Empirical support for this assumption has been provided by the studies of Gollwitzer and Bayer (2000) and Webb and Sheeran (2003) reported in Section 11.5.2. Whether the initial self-regulating task was to control one's emotions (Gollwitzer \& Bayer, 2000) or to perform well on a challenging task (the Stroop task; Webb \& Sheeran, 2003), implementation intentions successfully preserved self-regulatory resources. It would thus seem that self-regulation based on implementation intentions is not costly in terms of self-regulatory resources. 


\subsubsection{Implementation Intentions and Rebound Effects}

Wegner (1994) observed that conscious attempts to control or suppress one's thoughts - e.g., "I will not think about pink elephants!" - lead to rebound effects in the sense that the thoughts controlled become more readily accessible and thus more likely to surface in subsequent thoughts and behavior. Participants in his studies set themselves suppression goals of this kind and were instructed to ring a bell whenever theis thoughts-turned-in the proscrived direcnon. Participants with the goal of not thinking about pink elephants initially succeeded in suppressing these thoughts. However findings from a second phase of the experiment, in which participants engaged in free association and wrote down all of their thoughts, showed that participants who had resolved not to think about pink elephants in the first part of the experiment were now considerably more likely to report thoughts relating to pink elephants than participants who had not set a suppression goal. This is effect is termed the rebound effect:

- The rebound effect involves a marked increase in certain thoughts following the "extinction" of a goal to suppress or inhibit those thoughts.

Against the background of these research findings, it would seem reasonable to hypothesize that suppression-oriented implementation intentions may inhibit unwanted thoughts and feelings to begin with, but that these suppressed thoughts or feelings resurface later, i.e., that rebound effects occur. Gollwitzer et al. (2004) conducted two experiments to test this hypothesis. The participants in these studies were first asked to suppress stereotypical thoughts about a carefully described homeless person in an impression formation task. Rebound was measured either in terms of subsequent expression of stereotypes in a questionnaire tapping participants' evaluation of homeless people in general (Gollwitzer et al., 2004, Study 1) or in a lexical decision task assessing the cognitive accessibility of stereotypical contents regarding homeless people (Gollwitzer et al., 2004, Study 2). It emerged that the participants who had only set themselves the goal of suppressing stereotypical thoughts when forming an impression of the homeless person experienced pronounced rebound effects in both studies, showing more stereotypical judgments of homeless people in general (Study 1) and a higher accessibility of homeless stereotypes (Study 2). Participants who had furnished this goal intention with a corresponding implementation intention did not experience rebound effects.

\section{SUMMARY}

Findings on the potential costs of implementation intentions can be summarized as follows: implementation intentions do not lead to behavioral rigidity (e.g., in the suppression of prejudice or in performance on choice tasks),

implementation intentions do notlead to ego-depletion (e.g., performance levels are not reduced when emotions are controlled by means of implementation intentions), and

implementation intentions do not lead to rebound effects (e.g., when stereotypical thoughts are suppressed).

\subsection{Discussion and Future Perspectives}

\subsubsection{Implementation Intentions:}

\section{A Foolproof Self-Regulatory Strategy?}

Although implementation intentions seem to function effectively without significant costs in terms of behavioral rigidity, ego-depletion, or rebound, they do not always result in the desired outcome. First, the behavior specified in the then-part of an implementation intention may be beyond the person's control. For example, somebody who intends to eat healthily may plan to order vegetarian food, but then find themselves in a restaurant with no vegetarian options. Second, it makes no sense to specify situations that barely, if ever, occur in the if-part of implementation intentions. For example, it would be pointless for someone to plan to eat healthily by ordering vegetarian food the next time they go to a good restaurant if they usually eat in cafeterias or at home. Third, the behaviors specified in the then-part of the implementation intention may not be instrumental to reaching the goal. For example, someone who plans to eat healthily may order a vegetarian meal in a restaurant, not knowing that the dish chosen is full of fatty cheese.

\subsubsection{Prospective Memory and Neuronal Substrates}

In the past 20 years, implementation intention research has focused on motivational and volitional processes and their effects on impression formation and behavior. In the coming years, the focus should be shifted to cognitive and neuroscientific aspects. From the cognitive perspective, implementation intention research stands to benefit from prospective memory research (cf. Smith, 2003), which examines the processes by which intentions are stored in and retrieved from long-term memory, as well as from ongoing attempts to examine the different components of working memory (e.g., the central executive, the phonological loop, and the episodic buffer as proposed by Baddeley, 1986; Baddeley, 2000) and their functions in the realization of goal intentions and implementation intentions (Achtziger et al., forthcoming). From the neuroscientific perspective, researchers have already used magnetic encephalography to examine neuronal activity in the deliberative and implemental 
mindsets, and found that the implemental mindset is associated with higher posterior gamma activity than the deliberative mindset. These findings indicate that more intensive and complex brain activity is involved in planning the implementation of a goal in terms of when, where, and how to perform a specific goal-directed action than in weighing up the positive and negative consequences of a potential course of action and the probability that these consequences will occur. Moreover, the kind of brain activity generated by the implemental mindset seems to be associated with preparation of actions (Achtziger, Rockstroh, Oettingen, \& Gollwitzer, 2003). Research has also found the control of negative emotions (e.g., anxiety; Schweiger Gallo, Keil, Mc Culloch, Rockstroh \& Gollwitzer, forthcoming) and automatic stereotype activation (Achtziger, Moratti, Jaudas, Rockstroh, \& Gollwitzer, forthcoming) by means of implementation intentions vs. goal intentions to involve different electroencephalogram (EEG) responses. Generally speaking, however, there is still much to be learned about the neuronal substrates of action control by means of goal intentions vs. implementation intentions, and indeed about intentional states in general.

\section{SUMMARY}

The study of motivation in the course of action has made it possible to distinguish phenomena of goal setting (motivation) from phenomena of goal striving (volition). Whereas research to date has focused on the cognitive orientations associated with the respective action phases (mindset research), the aim of future research will be to identify self-regulatory strategies that facilitate effective accomplishment of the tasks necessary at each phase in the course of action. The theory of intentional action control (Gollwitzer, 1993, 1999) has taken first steps in this direction, showing how implementation intentions can facilitate the performance of tasks that necessitate the initiation of goal-directed behavior, the shielding of that behavior against distractions, the timely termination of goal striving, and measures to ensure that the capacity for action control is not overstretched during goal striving.

Future research should take a two-pronged approach. On the one hand, it should seek to identify further self-regulatory strategies that help to address these kinds of difficulties and thereby help people to attain their goals; on the other hand, the search for effective self-regulatory strategies should be extended to other action phases. The predecisional phase of goal setting has already been examined. Fantasy realization theory (Oettingen, 1996, 2000) distinguishes three different goal setting strategies (mental contrasting of desired future and actual present, indulging in positive fantasies about the future, and dwelling on negative aspects of the present), and has found that only mental contrasting guarantees that the goals people set are in line with their perceived expectations of success. In other words, mental contrasting ensures that people do not pursue goals that are excessively high or low, but aspire to goals that help them realize their full potential. Future research should examine the postactional phase in which completed goal strivings are evaluated, and seek to identify self-regulatory strategies that are conducive to a person's goal striving in subsequent endeavors. The ultimate goal of this research is to develop intervention programs that will provide individuals with action control strategies that enable them to address the problems that beset goal striving in the different action phases of the Rubicon model more successfully.

\section{REVIEW QUESTIONS}

1. Which four phases are distinguished in the Rubicon model of action phases?

The predecisional, preactional, actional, and postactional phase.

2. At the end of which phase of the Rubicon model does the individual "cross the Rubicon" by committing to a goal intention?

At the end of the predecisional phase.

3. What effects do the deliberative vs. implemental mindsets have on self-evaluation?

Studies have shown that an implemental mindset is associated with more positive self-evaluations than a deliberative mindset.

4. How are the implemental and deliberative mindsets experimentally manipulated?

There are two methods of inducing each mindset: Implemental mindset: 1. Participants are asked to choose between alternatives, i.e., to make a decision; 2. Participants are asked to plan the steps required to translate a given project into action, specifying when, where, and how to take each step.

Deliberative mindset: 1. Participants are interrupted during the decision-making process; 2. Participants weigh the positive and negative short- and long-term consequences of making or failing to make a change decision.

5. What effects do the deliberative vs. implemental mind- sets have on information processing?

Individuals in the deliberative mindset generally engage in more "deliberative" thoughts, are able to recall deliberative thoughts better than implemental thoughts, and tend to be open-minded (i.e., to process information in an objective and unbiased manner); moreover, their attention is not centrally focused. The opposite effects are observed for individuals in the implemental mindset.

6. After induction of which mindset are goals more likely to be attained?

After induction of the implemental mindset. 
7. What are the effects of a deliberative mindset on people's evaluations of their romantic relationships?

It depends on the person's commitment to the relationship. If commitment is high, the partner is rated more positively after induction of a deliberative mindset than after induction of an implemental mindset; if commitment is low, the effects are reversed.

8. What is a "goal intention"?

Goal intentions specify desired end states that people wish to attain. They have the structure "I-Intend_toreach $X$."

\section{What is an "implementation intention"?}

Implementation intentions are "if-then" statements that specify the conditions under which goal-directed behavior is to be initiated.

10. What function do implementation intentions serve? Implementation intentions facilitate the enactment of goal intentions that are particularly difficult to attain.

11. Which factors moderate the effects of implementation intentions?

The following moderator variables have been identified: difficulty of the goal intention, commitment to the goal intention, commitment to the implementation intention,

degree of activation of the goal intention.

12. Are cognitive resources required to putimplementation intentions into practice?

Implementation intentions are initiated automatically and thus do not tax cognitive resources.

13. What positive effects can implementation intentions have on health-related behavior?

Exampies: reguiar intake of vitamin tabiets; participation in cancer screening; regular exercise after hip replacement surgery.

14. How can implementation intentions inhibit unwanted effects, such as stereotypical views of others?

Unwanted behavior can be inhibited by forming an implementation intention that inhibits either its activation or its application. The if part of the implementation intention should specify a situation or a stimulus that is likely to trigger activation or application of the stereotype; the then part should specify a goal-directed behavior with the potential to inhibit the stereotype (e.g., by initiating or upholding individualized processes of impression formation). 